Docosahexaenoic acid and oleic acid induce altered DNA methylation of individual CpG loci in Jurkat $\mathbf{T}$ cells

J. Eduardo Pérez-Mojica ${ }^{1}$, Karen A. Lillycrop² ${ }^{2}$ Cyrus Cooper $^{3}$, Philip C. Calder ${ }^{1}$, Graham C. Burdge $^{1}$

${ }^{1}$ School of Human Development and Health, Faculty of Medicine, University of Southampton, Southampton, UK.

${ }^{2}$ Centre for Biological Science, Faculty of Natural and Environmental Sciences, University of Southampton, Southampton, UK.

${ }^{3}$ MRC Lifecourse Epidemiology Unit, University of Southampton, Southampton General Hospital, Southampton, UK

Correspondence to: Professor G.C. Burdge, School of Human Development and Health, Institute of Developmental Sciences Building (MP887), Faculty of Medicine, University of Southampton, Southampton General Hospital, Tremona Road, Southampton, SO16 6YD, UK. g.c.burdge@soton.ac.uk. Telephone +44(0)2381205259

\title{
Financial support
}

The study was funded by The Medical Research Council (UK) and The National Council for Science and Technology (CONACYT) (Mexico).

Key words Docosahexaenoic acid, Oleic acid, DNA methylome, PPAR $\alpha$, Response element, Jurkat cells.

\section{Abbreviations}

DHA, docosahexaenoic acid; pTRE, putative transcription factor response element; PPARRE peroxisomal proliferator activated receptor response element; PUFA, polyunsaturated fatty acid 


\begin{abstract}
Docosahexaenoic acid (DHA, 22:6n-3) and oleic acid (18:1n-9) can alter the DNA methylation of individual $\mathrm{CpG}$ loci in vivo and in vitro, although the targeting mechanism is unknown. We tested the hypothesis that the targeting of altered methylation is associated with putative transcription factor response elements (pTREs) proximal to modified loci. Jurkat cells were treated with 22:6n-3 or 18:1n-9 (both $15 \mu \mathrm{M}$ ) for eight days and DNA methylation measured using the MethylationEPIC $850 \mathrm{~K}$ array. $1596 \mathrm{CpG}$ loci were altered significantly (508 hypermethylated) by 22:6n-3 and 563 CpG loci (294 hypermethylated) by 18:1n-9. 78 loci were modified by both fatty acids. Induced differential methylation was not modified by the PPAR $\alpha$ antagonist GW6471. DNA sequences proximal to differentially methylated $\mathrm{CpG}$ loci were enriched in zinc-finger pTREs. These findings suggest that zinc-finger-containing transcription factors may be involved in targeting altered DNA methylation modifying processes induced by fatty acids to individual $\mathrm{CpG}$ loci.
\end{abstract}




\section{Introduction}

Fatty acids can modify cell function by influencing cell membrane fluidity and, consequently the activity of integral proteins, by changing the nature of lipid second messengers and by altering the expression of the transcriptome, for example via the induction of peroxisome proliferator-activated receptor (PPAR) activity [1]. In addition, there is increasing evidence that fatty acids can alter cell function via inducing changes in epigenetic processes [2]. For example, feeding pre-pregnant and pregnant mice diets with different 18:2n-6:18:3n-3 ratios has been shown to induce in the offspring modest changes in the mean DNA methylation of the Fads2 promoter [3]. The offspring of pregnant rats fed diets with different saturated or polyunsaturated fatty acid (PUFA) contents induced in the offspring hypermethylation, up to a $20 \%$ difference in DNA methylation, of specific CpG loci in the Fads2 promoter and decreased mRNA expression of the gene [4]. Dietary supplementation of humans with either omega-3 PUFA, ethyl esters of 20:5n3, 22:5n-5 and 22:6n-3, or olive oil induced CpG locus-specific changes in the DNA methylation of FADS2 and ELOVL5, but not FADS1 or ELOVL2, which differed in locus, direction and magnitude between dietary supplements and between men and women, which was reproducible in two cohorts [5]. Dietary supplementation of pregnant women with 22:6n-3 induced modest $(<5 \%)$ changes in the DNA methylome of their infants [6]. Moreover, incubation of U937 leukaemic cells with 20:5n-3 induced demethylation of a single CpG locus in the CC/AAT/enhancer binding protein- $\delta$ promoter and increased expression of the gene, while there was no effect of incubation with 18:1n-9 $[7,8]$. Treatment of THP-1 monocytes with either 20:4n-6 or 18:1n-9 induced fatty acid concentration-related changes in global DNA methylation [9]. Overall, fatty acids can alter the epigenetic regulation of specific genes in a manner that appears to depend upon the type of fatty acid used. However, the mechanisms by which fatty acids induce locus-specific changes in DNA methylation are not known, although binding of PPAR $\alpha$ to its response element has been suggested to be involved in the targeting of the fatty acid to individual CpGs [9].

To address this mechanism, we determined the effect of incubating Jurkat $\mathrm{T}$ cells with either 22:6n-3 or 18:1n-9 on the DNA methylome using the MethylationEPIC $850 \mathrm{~K}$ array. We then investigated whether PPAR $\alpha$ was involved in the induction of altered DNA methylation of individual $\mathrm{CpG}$ loci, and if differentially methylated loci were enriched for specific transcription factor binding sites.

\section{Materials and methods}

\subsection{Cell culture}

Jurkat cells were maintained in RPMI-1640 medium (Sigma-Aldrich, Dorset, UK) supplemented 
with 9\% (v/v) fetal bovine serum (Life Technologies, Renfrewshire, UK), 2 mM L-glutamine, 100 $\mathrm{U} / \mathrm{mL}$ penicillin and $100 \mu \mathrm{g} / \mathrm{mL}$ streptomycin (Sigma-Aldrich, Dorset, UK) and incubated at $37{ }^{\circ} \mathrm{C}$ in an atmosphere containing 5\% (v/v) $\mathrm{CO}_{2}$. Cells were treated with either 22:6n-3 or 18:1n-9 (both $15 \mu \mathrm{M})($ Sigma-Aldrich, Dorset, UK) or ethanol carrier (final concentration $<0.05 \%(\mathrm{v} / \mathrm{v}))(\mathrm{n}=12$ replicate cultures per treatment) for up to 8 days. The concentrations of $18: 1 n-9$ and $22: 6 n-3$ were comparable to those reported in human blood lipids [10]. In some experiments, Jurkat cells were treated with the PPAR $\alpha$ antagonist GW6471 $(2 \mu \mathrm{M})$ (both Bio-Techne, Oxfordshire, UK) plus 22:6n-3 $(15 \mu M)(n=8$ replicate cultures per treatment). In all experiments, culture medium was replaced every 72 hours. Cell viability was measured by trypan blue exclusion (Sigma-Aldrich, Dorset, UK). At the end of the incubation period, cells were harvested by centrifugation, washed three times with phosphate-buffered saline (PBS) (Sigma-Aldrich, Dorset, UK) and stored at -80 ${ }^{\circ} \mathrm{C}$.

\subsection{Measurement of fatty acid composition by gas chromatography}

The fatty acid composition of the cells was determined essentially as described previously [11]. Cells $\left(8 \times 10^{6}\right)$ were washed three times with PBS and resuspended in $0.9 \%(\mathrm{w} / \mathrm{v}) \mathrm{NaCl}(0.8 \mathrm{ml})$. Chloroform/ methanol 2:1 (v/v) (5 ml) (Fisher-Scientific, Leicestershire, UK) containing butylated hydroxytoluene $(50 \mathrm{mg} / \mathrm{l})$ and $1 \mathrm{M} \mathrm{NaCl}(1 \mathrm{ml})$ were added, the samples vortexed, and the organic phase then collected and dried under $\mathrm{N}_{2}$ [12]. The dried extract was dissolved in toluene and fatty acid methyl esters (FAME) were synthesised by incubation with methanol containing $2 \%(\mathrm{v} / \mathrm{v})$ sulphuric acid at $50^{\circ} \mathrm{C}$ for 2 hours [11]. FAME were extracted with hexane and resolved on a BPX70 fused silica capillary column $(32 \mathrm{~m} \times 0.25 \mathrm{~mm} \times 25 \mu \mathrm{m}$; SGE Analytical Science $)$ using an Agilent 6890 gas chromatograph equipped with flame ionisation detection (Agilent Technologies Ltd) [10]. Peaks were identified by comparison of retention times with authentic standards (Supelco® 37 Component FAME Mix, Sigma).

\subsection{Analysis of DNA methylation}

Genomic DNA was extracted using QIAamp DNA Blood Mini Kit (Qiagen, Manchester, UK) according to the manufacturer's instructions. DNA concentration and purity were measured using a NanoDrop ND-1000 full-spectrum $(\lambda=220-750 \mathrm{~nm})$ spectrophotometer (Thermo Scientific, UK) where $\lambda=260 / 280$ and $\lambda=260 / 230$ ratios were all $1.8( \pm 0.1)$ and $2.2( \pm 0.2)$, respectively. DNA samples with the highest concentration $(n=4$ replicate cultures per treatment) were then analysed using the Infinium MethylationEPIC 850K array (Illumina, San Diego, CA) that measured the DNA methylation status of $864,935 \mathrm{CpG}$ sites by single-base extension [13]. Array 
hybridisation was carried out by the Centre for Molecular Medicine and Therapeutics, BC Children's Research Hospital Institute, University of British Columbia, Vancouver, Canada. Raw data were analysed with the R package minfi version 1.18.6 [14] with MethylationEPIC annotation ilm10b2.hg19_0.3.0 and the R version 3.3.0 of the IRIDIS 4 High-Performance Computing Facility at the University of Southampton (Southampton, UK). Standard quality controls and normalisation procedures were followed for the data pre-processing [15]. 1,047 (22:6n-3) and 1,038 (18:1n-9)

poor quality probes were excluded from the analysis according to a mean detection p-value $>0.05$ of the absolute signal (methylated + unmethylated) compared to background [15]. 28,931 (22:6n-3) and 28,928 (18:1n-9) SNP disrupting probes were also excluded from the analysis [16]. Normalisation was carried out using functional normalisation (Funnorm) which clustered the $\beta$ densities of all samples as expected (Supplemental Figure 1) [17]. Complete removal of batch effects was achieved using the ComBat function (Supplemental Figure 2) [18] included in the sva R package. Samples were categorically clustered and $\mathrm{CpG}$ loci with $\mathrm{P}$-value $<0.05$, q-value $<0.05$ (Benjamini and Hochberg False Discovery Rate for multiple testing correction [19]) and a $\beta$-value $>$ 0.05 were considered to be differentially methylated. An overview of analysis workflow is shown in Supplemental Figure 3.

\subsection{Pyrosequencing}

Pyrosequencing was performed as described previously [20]. Briefly, genomic DNA (1 $\mu \mathrm{g})$, EpiTect Control DNA unmethylated (Qiagen, West Sussex, UK) and CpGenome ${ }^{\mathrm{TM}}$ Universal Methylated DNA (Millipore, Hertfordshire, UK) were bisulphite converted using the EZ DNA Methylation-Gold ${ }^{\mathrm{TM}}$ Kit (Cambridge Bioscience, Cambridge, UK) according to the manufacturer's instructions. PCR was then performed using bespoke primers (Table 1) (Eurofins Genomics, Ebersberg, Germany) in a final reaction volume of $25 \mu 1.45$ PCR cycles were performed, each cycle comprising of denaturation at $95^{\circ} \mathrm{C}$ for $15 \mathrm{~s}$, annealing at probe-specific temperature (Table 1) for $30 \mathrm{~s}$ and extension at $72{ }^{\circ} \mathrm{C}$ for $15 \mathrm{~s}$ using KAPA2G Robust HotStart ReadyMix Kit (Kapa Biosystems, Massachusetts, USA). PCR amplification was assessed using agarose gel electrophoresis. Pyrosequencing was carried out as described [21]. Briefly, PCR products were immobilised on Streptavidin Sepharose ${ }^{\circledR}$ High-Performance beads (34 $\mu$ m, GE Healthcare Life Sciences, Buckinghamshire, UK), washed, denatured and eluted into annealing buffer that contained the sequencing primers (Table 1). DNA methylation was measured using the SQA kit on a PSQ 96MA Pyrosequencer (Biotage AB, Kungsgatan, Sweden). Percent DNA methylation was calculated using Pyro Q CpG software (Biotage). 


\subsection{Pathway analyses}

Canonical pathways enriched for differentially methylated genes were identified using Ingenuity ${ }^{\circledR}$ Pathway Analysis (IPA ${ }^{\circledR}$ ) software (QIAGEN Bioinformatics). Analysis was carried out using the built version: 400896M, content version: 28820110 (release date: 2018-09-24). All CpG loci with significantly altered DNA methylation within any genic region were considered for analysis. Excluding duplicates, 935 or 348 genes in cells treated with 22:6n-3 or 18:1n-9, respectively, were mapped by the IPA ${ }^{\circledR}$ software and included in the analysis. Statistical significance was assumed at $\mathrm{P}$ $<0.05$ from Fisher's exact performed in IPA ${ }^{\circledR}$ using a dataset containing all genes included in the $850 \mathrm{~K}$ array (background restricted).

\subsection{DNA Motif Analysis}

All differentially methylated CpG loci in cells treated with $22: 6 n-3$ or 18:1n-9 were tested for the presence of DNA motifs and compared to $1 \times 10^{5}$ unmodified $\mathrm{CpG}$ loci as control. The number for control $\mathrm{CpG}$ loci was the maximum number possible to use that was unaltered in the same genomic context. To cover the majority of DNA binding sites in eukaryotes (typically $<30 \mathrm{bp}$ in length) [22] we screened \pm 60 bp proximal to each $\mathrm{CpG}$ locus. To increase reliability of the results, motif analysis was carried out using two different publicly available tools, namely Multiple EM (Expectation maximisation algorithm) for Motif Elicitation (MEME) and Hypergeometric Optimisation of Motif EnRichment (HOMER) [23, 24]. De novo motif discovery was performed in both tools using discriminative analysis with zero or one occurrence per sequence (ZOOPS) scoring. DNA motifs with an expected value (E-value) $\leq 1 \times 10^{-10}$ by MEME or HOMER were then compared using the similarity, tree-building, and alignment of DNA motifs and profiles (STAMP) tool $[25,26]$. Only similar motifs (STAMP E-value $<0.05$ ) identified by both tools were individually compared with the core collection of the HOmo sapiens COmprehensive MOdel COllection (HOCOMOCO) v11 using the Tomtom tool in the MEME Suite [27, 28]. DNA motifs with an E-value $<0.05$ and q-value $<0.05$ were considered to be similar to putative response elements. An overview of the motif analysis workflow is shown in Supplemental Figure 4.

\subsection{Statistics}

Statistical analyses were carried out using IBM SPSS® version 22.0.0.0, 64-bit edition. Statistical significance was assumed at $\mathrm{P}<0.05$. Controls versus treatment means were compared using either Students t-test or ANOVA as specified in the table or figure legend. 


\section{Results}

3.1 Effect of 22:6n-3 and 18:1n-9 treatment on the fatty acid composition and viability of Jurkat cells

Treatment of Jurkat cells with 22:6n-3 for 8 days increased the proportions of 22:6n-3 (11.9fold), 16:0 (1.5-fold), 18:0 (1.4-fold), 20:3n-3 (2.1 -fold), 20:5n-3 (3.8 -fold) and 22:5n-3 (2.2 fold), and decreased the proportions of 16:1n-7 (1.26-fold), 18:1n-9 (1.1-fold) and 18:1n-7 (-1.26fold) (Figure 1A). Incubation of Jurkat cells with 18:1n-9 for 8 days increased the proportions of 18:1n-9 (2.9-fold), 16:0 (1.2-fold) and 20:1n-9 (4.4-fold), but decreased the proportion of 16:1n-7 (1.3-fold) (Figure 1B). The viability of Jurkat cells treated with $18: 1 n-9$ or $22: 6 n-3$ was $>90 \%$ throughout the experiments.

\subsection{Effect of fatty acid treatment on DNA methylation in Jurkat Cells}

Unsupervised principle component analysis of all $\mathrm{CpG}$ loci included in the array did not show complete divergence between treatment groups (Figure 2A). However, restricting the analysis to differentially methylated $\mathrm{CpG}$ loci $(\mathrm{P}<0.05$; q-value $<0.05, \Delta \beta>0.05)$ showed complete clustering of samples according to treatment (Figure 2B).

$1596 \mathrm{CpG}$ sites were differentially methylated (P-value $<0.05$, q-value $<0.05, \beta$-value $>$ 0.05 ) in Jurkat cells treated with 22:6n-3 compared to controls, of which 508 (32\%) were hypermethylated (Figure 3A). $563 \mathrm{CpG}$ loci were differentially methylated in cells treated with 18:1n-9, of which 294 (52\%) were hypermethylated (Figure 3B). $78 \mathrm{CpG}$ loci that were differentially methylated (26 (33\%) hypermethylated) in cells treated with 22:6n-3 were also differentially methylated in cells treated with 18:1n-9. The direction of change in methylation of CpG loci that were altered by both 22:6n-3 and 18:1n-9 was the same for both treatments (Figure 3; Supplemental Table 2).

\subsection{The genomic distribution of differentially methylated $C p G$ loci in Jurkat cells treated with 22:6n-3 or $18: 1 n-9$}

The ratio of $\mathrm{CpG}$ altered to $\mathrm{CpG}$ measured was calculated in order to adjust the data for any effect of the distribution bias of $\mathrm{CpG}$ loci detected by the $850 \mathrm{~K}$ array in genic regions (defined here as the region $-1500 \mathrm{bp}$ to the transcription start site to the 3' UTR, $\mathrm{n}=616,132$ loci) compared to intergenic regions $(n=248,803$ loci). Treatment with 22:6n-3 induced differential DNA methylation of $0.16 \% \mathrm{CpG}$ loci at genic regions and $0.24 \% \mathrm{CpG}$ loci at intergenic regions. 18:1n-9 induced differential DNA methylation on $0.06 \% \mathrm{CpG}$ loci at genic regions and $0.09 \% \mathrm{CpG}$ loci at intergenic regions. A higher ratio in $\mathrm{CpG}$ loci within intergenic regions compared to $\mathrm{CpG}$ loci 
within genic regions was also observed when altered $\mathrm{CpG}$ loci were analysed according to the direction of change in DNA methylation. Incubation with 22:6n-3 induced hypermethylation of $0.05 \% \mathrm{CpG}$ loci in genic regions and $0.07 \%$ in intergenic regions. $22: 6 \mathrm{n}-3$ induced hypomethylation of $0.11 \%$ loci in genic regions and $0.17 \%$ loci in intergenic regions. Incubation with $18: 1 n-9$ induced hypermethylation of $0.03 \%$ loci in genic sequences and $0.05 \%$ loci in intergenic regions. $18: 1 \mathrm{n}-9$ also induced hypomethylation of and $0.03 \%$ loci in genic regions and $0.04 \%$ loci in intergenic regions.

\subsection{Pathway analysis of differentially methylated genes in Jurkat cells treated with 22:6n-3 or} $18: \ln -9$

Treatment with 22:6n-3 or 18:1n-9 changed the DNA methylation of 988 or 345 CpG loci, respectively, in genic regions. Genes with altered DNA methylation induced by 22:6n-3 were enriched in genes involved in Synaptic Long-Term Potentiation, Synaptic Long-Term Depression, Protein Kinase A Signalling, and Netrin Signalling canonical pathway (Table 2). Genes with altered DNA methylation induced by 18:1n-9 were associated with Amyotrophic Lateral Sclerosis Signalling, Opioid Signalling Pathway, Aryl Hydrocarbon Receptor Signalling, and Clathrinmediated Endocytosis Signalling canonical pathways (Table 2).

\subsection{Validation of 850 K array by pyrosequencing}

The methylation status of loci that were shown to be differentially methylated on the $850 \mathrm{~K}$ array was validated by pyrosequencing. Three $\mathrm{CpG}$ loci that had lower DNA methylation (ID cg26292058, cg05475386, and cg27188282) and two CpG loci that had higher DNA methylation (ID cg06989443 and cg22518417) than controls after incubation with 22:6n-3 were used for validation analysis. These loci were within the top twenty most differentially methylated CpG loci and were within a sequence that allowed primer design. All CpG loci analysed by pyrosequencing showed a significant change on DNA methylation in the same direction as the $850 \mathrm{~K}$ array. The magnitude of DNA methylation change in treatments compared with controls was comparable between both methods (Supplemental Table 1).

\subsection{Time course of the induction of altered DNA methylation by 22:6n-3}

The level of methylation of the $5 \mathrm{CpG}$ loci used for array validation was measured by pyrosequencing after incubation with 22:6n-3 for 3, 6 and 8 days. There was a significant treatment effect and a significant time*treatment effect on the methylation status of cg26292058 (treatment $\mathrm{P}$ $<0.0001$; time*treatment $\mathrm{P}=0.002$ ), cg05475386 (treatment $\mathrm{P}<0.0001$; time*treatment $\mathrm{P}=$ 
0.006), cg6989443 (treatment and time*treatment both $\mathrm{P}<0.0001$ ) and $\operatorname{cg} 22518417$ (treatment $\mathrm{P}<$ 0.0001; time*treatment $\mathrm{P}=0.002)$, and a significant effect of treatment on $\operatorname{cg} 27188282(\mathrm{P}=0.001)$. 18:1n-9 did not alter the methylation status of any of the CpG loci measured (Figure 4). Incubation with 22:6n-3 altered the methylation status of cg26292058, cg27188282 and cg22518417 compared to untreated cells by 8 days, but not at earlier time points, while the methylation status of the other $\mathrm{CpG}$ loci that were measured differed from untreated cells by 6 days (Figure 4).

\subsection{The effect of treatment with a PPAR $\alpha$ antagonist on induction of altered DNA methylation by}

\section{$22: 6 n-3$}

The PPAR $\alpha$ antagonist GW6471 has been shown to inhibit induction of altered DNA methylation by 20:4n-6 in THP-1 monocytes [9]. Therefore, we investigated whether GW6471 altered the effect of $22: 6 n-3$ on the DNA methylation status of the $5 \mathrm{CpG}$ loci used for array validation. There was a significant effect on the methylation status of all 5 candidate loci (all $\mathrm{P}<0.01)$ in cells treated with 22:6n-3 only or 22:6n-3 plus GW6471 (Figure 5). However, there was no significant difference in the change in DNA methylation induced by $22: 6 n-3$ and that induced by $22: 6 n-3$ plus GW6471 at these $5 \mathrm{CpG}$ loci.

\subsection{Identification of DNA motifs in sequences containing differentially methylated CpGs in cells} treated with 22:6n-3 or $18: 1 n-9$

DNA motif analysis was carried out using data obtained from Jurkat cells treated with 22:6n-6 or 18:1n-9. Twenty-seven pTREs were significantly aligned $(\mathrm{P}<0.0001$, E-value $<0.05$ and q-value $<0.05)$ with sequences that contained differentially methylated $\mathrm{CpG}$ loci in cells treated with 22:6n-3 and/or 18:1n-9. These pTREs included members of the Kruppel-like factor family, the specificity protein family and zinc finger proteins (Table 3). Twelve pTREs were aligned with sequences containing differentially methylated $\mathrm{CpG}$ loci in cells treated with 22:6n-3, two pTREs were aligned with differentially methylated CpGs in cells treated with 18:1n-9, and the remaining thirteen pTREs were associated with differentially methylated $\mathrm{CpG}$ loci in cells treated with either fatty acid. 22/27 of the pTREs that were identified interact with transcription factors that contain a zinc finger type Cys2-His2 DNA binding domain (Table 3). There did not appear to be any simple pattern of association between fatty acid treatment and the nature of the DNA binding domain of proteins that bind to the PTREs that were associated with differentially methylated CpG loci (Table 3). The PPAR $\alpha$ response element was not aligned significantly with differentially methylated CpGs.

\section{Discussion}


Together these findings showed that incubation with either 22:6n-3 and 18:1n-9 at a physiologically relevant concentration can induce $\mathrm{CpG}$ locus-specific changes in DNA methylation in Jurkat cells that were contingent on the type of fatty acid. Such differentially methylated CpG loci were enriched in intergenic regions and were aligned with pTREs for several transcription factors, some of which distinguished between treatment with 22:6n-3 and those treated with $18: 1 n-9$.

As expected, incubation with either 22:6n-3 or 18:1n-9 increased the proportions of these fatty acids in fatty acids in Jurkat cells. The increased proportions of 22:5n-3, 20:5n-3 and 20:3n-3 in cells treated with 22:6n-3 suggests retro-conversion of 22:6n-3 to shorter chain, less unsaturated fatty acids by the pathway reported previously to involve peroxisomal fatty acid $\beta$-oxidation [29, 30]. The increase in the proportion of 20:1n-9 in cells treated with 18:1n-9 is consistent with chain elongation of this fatty acid. The increase in the proportions of saturated and monounsaturated fatty acids in cells treated with 22:6n-3 may have been due fatty acid $\beta$-oxidation and carbon recycling via fatty acid synthesis de novo [31], while the reciprocal changes in the proportions of 16:0 and 16:1n-7 suggest feedback inhibition of $\Delta 9$ desaturase by 18:1n-9.

The Illumina $850 \mathrm{~K}$ array was used to provide the widest coverage of the effects of fatty acids on the DNA methylome reported to date. The changes in DHA methylation that were detected by the array were validated by pyrosequencing. Experiments in humans $[5,6,32]$. animal models $[3,4$, 33], and in cultured cells [7, 9] have suggested that, based on analysis of candidate genes or lower coverage DNA methylation arrays, fatty acids can induce differential changes in the methylation status of individual $\mathrm{CpG}$ loci and that the pattern of such changes is related to the fatty acid treatment. The present findings support this view by showing that treatment with $22: 6 n-3$ induced a change in methylation status of almost three-fold more $\mathrm{CpG}$ loci than were altered by $18: 1 \mathrm{n}-9$ treatment while the methylation status of only 78 loci was changed with both fatty acids. This agrees with the findings of a study in which THP-1 cells were incubated with either arachidonic acid (20:4n-3) or 18:1n-9 in that the number of altered CpG loci was greater in cells treated with 20:4n-6 than those incubated with 18:1n-9 [9], and also with in vivo dietary modification studies in humans [5] and rodents [4]. The present findings show that 22:6n-3 tended to induce a smaller proportion of hypermethylated loci than 18:1n-9 in Jurkat cells, while 20:4n-4 had a greater tendency to increase the methylation status of $\mathrm{CpG}$ loci compared to $18: 1 \mathrm{n}-9$ in THP-1 cells [9]. The intergenic $>$ genic distribution of altered $\mathrm{CpG}$ loci may indicate that fatty acids may preferentially alter DNA methylation in DNA regulatory elements than coding regions.

The pathways that were most enriched for altered CpGs differed markedly between Jurkat cells treated with 22:6n-3 and those treated with 18:1n-9. Pathways enriched with altered CpGs in 
cells treated with 22:6n-3 included two related to the cancer phenotype, namely Netrin Signalling [34] and Protein Kinase A Signalling [35] which may be consistent with reported effects of 22:6n-3 on cancer cells [36]. The possible functional significance in leukaemia cells of enrichment of pathways involved in axonal growth and signalling cannot be easily deduced based on current knowledge. The pathways enriched in differentially methylated CpG loci in cells treated with 18:1n-9 were primarily involved in trans-membrane cell signalling and cell differentiation. Overall, current and previous findings suggest that although a range of fatty acids can alter DNA methylation, capacity of PUFA to alter the DNA methylome appears to be greater than for other fatty acid classes, although such effects may differ between cell types.

Previous studies of the effect of fatty acids on DNA methylation in cultured cells used incubation periods of 24 hours [7, 9, 37]. The present findings show that there was no statistically significant change in DNA methylation of the five candidate loci in cells treated with 22:6n-3 before 72 hours. This suggests that the changes in DNA methylation induced by fatty acids may be a multi-step or multi-factor process. For example, increased methylation requires recruitment of a DNA methyltransferase (DNMT) [37, 38]. Active demethylation has been suggested to involve the activities of several enzymes including ten-eleven translocases (TET) [39-41], methyl binding domain protein (MBD)2b [42], MBD4 [43], the DNA repair endonuclease XPG (Gadd45a) [44] and a G/T mismatch repair DNA glycosylase [45]. PPAR $\alpha$ has been implicated in mediating the effects of 20:4n-3 on DNA methylation in THP-1 monocytes, while PPAR $\gamma$ has been shown to interact with TET2[46]. Thus, it possible that members of the PPAR family of fatty acid-binding transcription factors may be involved in targeting of TET activity to specific CpG loci, although it is currently not known whether PPAR $\alpha$ can interact with TET proteins. PPAR $\alpha$ can act with DNMT1 [47], but the mechanism of this interaction is not known. Thus, it is plausible that PPARs may have a role in mediating the targeting of DNA methyltransferase and/or DNA demethylase activity to individual $\mathrm{CpG}$ loci. However, the present study did not find evidence of the involvement of PPAR $\alpha$ in mediating the effects of 22:6n-3 on DNA methylation in five candidate loci. Instead, several pTREs were identified that aligned with DNA sequencings which were proximal to differentially methylated $\mathrm{CpG}$ loci. The majority of these pTREs interact with transcription factors that contain zinc-finger DNA binding domains. This suggests that zinc-finger proteins are involved in targeting fatty acid-induced changes in DNA methylation to specific loci, although it is also possible that this observation may reflect the abundance of these DNA binding motifs in the human proteome [48]. Moreover, WT1 been shown to recruit Tet2 to its response element in HL60 cells [49] and SP1 has shown to interact with DNMT1 in HEK293 cells [50]. 
Thus, it is possible that WT1 and SP1 may facilitate targeting of DNA methyltransferase or demethylase activities to specific $\mathrm{CpG}$ loci.

\section{CONCLUSIONS}

Overall, these findings show that incubation with 22:6n-3 or 18:1n-9 induced CpG locus-specific DNA methylation changes in Jurkat cells which occurred over different periods time contingent on the CpG locus. Differentially methylated CpG loci were associated with pTREs which may provide a mechanism for mediating locus-specific changes in DNA methylation by fatty acids. Since differential methylation of individual $\mathrm{CpG}$ loci has been shown to predict traits that are associated with risk of cardiometabolic disease [51-54], one implication of the present findings is that it may be possible to develop dietary interventions based on specific combinations of fatty acids to modify the methylation status of disease-associated $\mathrm{CpG}$ loci.

\section{ACKNOWLEDGEMENTS}

We wish to thank Dr Michael Kobor's group at the Centre for Molecular Medicine and Therapeutics, British Columbia Children's Research Hospital Institute, University of British Columbia, Vancouver, Canada for carrying out the $850 \mathrm{~K}$ methylation array hybridisation.

\section{AUTHOR CONTRIBUTIONS}

GCB and KAL designed the study and, together with CC and PCC, supervised the work. JEP-M carried out the experiments and analysed the data. GCB and JEP-M wrote the manuscript with input from all authors.

\section{AUTHOR DECLARATIONS}

GCB has received research funding from Nestle, Abbott Nutrition and Danone. He has served as member of the Scientific Advisory Board of BASF and is member of the BASF Asia Grant Panel. PCC acts as a consultant to BASF AS, Cargill, Smartfish, DSM and Fresenius-Kabi. The authors state they have no conflicts of interest related to the work presented in this manuscript. None of the other authors has disclosures or conflicts of interest to report. 


\section{References}

[1] G.C. Burdge, Is essential fatty acid interconversion an important source of polyunsaturated fatty acids in humans?, Br J Nutr 27 (2018) 1-28.

[2] G.C. Burdge, K.A. Lillycrop, Fatty acids and epigenetics, Current opinion in clinical nutrition and metabolic care, 17 (2014) 156-161.

[3] M.D. Niculescu, D.S. Lupu, C.N. Craciunescu, Perinatal manipulation of alpha-linolenic acid intake induces epigenetic changes in maternal and offspring livers, FASEB J 27 (2013) 350-358. [4] S.P. Hoile, N.A. Irvine, C.J. Kelsall, et al. Maternal fat intake in rats alters 20:4n-6 and 22:6n-3 status and the epigenetic regulation of Fads2 in offspring liver, The Journal of nutritional biochemistry, (2012).

[5] S.P. Hoile, R. Clarke-Harris, R.C. Huang, et al. Supplementation with n-3 Long-Chain Polyunsaturated Fatty Acids or Olive Oil in Men and Women with Renal Disease Induces Differential Changes in the DNA Methylation of FADS2 and ELOVL5 in Peripheral Blood Mononuclear Cells, PLoS One, 9 (2014) e109896.

[6] S.J. van Dijk, J. Zhou, T.J. Peters, et al. Effect of prenatal DHA supplementation on the infant epigenome: results from a randomized controlled trial, Clin Epigenetics, 8 (2016) 114.

[7] V. Ceccarelli, S. Racanicchi, M.P. Martelli, et al., Eicosapentaenoic acid demethylates a single $\mathrm{CpG}$ that mediates expression of tumor suppressor CCAAT/enhancer-binding protein delta in U937 leukemia cells, Journal of Biological Chemistry, 286 (2011) 27092-27102.

[8] V. Ceccarelli, G. Nocentini, M. Billi, et al. Eicosapentaenoic acid activates RAS/ERK/C/EBPbeta pathway through H-Ras intron $1 \mathrm{CpG}$ island demethylation in U937 leukemia cells, PLoS One, 9 (2014) e85025.

[9] G.A. Silva-Martinez, D. Rodriguez-Rios, Y. Alvarado-Caudillo, et al., Arachidonic and oleic acid exert distinct effects on the DNA methylome, Epigenetics, 11 (2016) 321-334.

[10] A.L. West, E.A. Miles, K.A. Lillycrop, et al., Postprandial incorporation of EPA and DHA from transgenic Camelina sativa oil into blood lipids is equivalent to that from fish oil in healthy humans, Br J Nutr, (2019) 1-27.

[11] A.L. West, G.C. Burdge, P.C. Calder, Lipid structure does not modify incorporation of EPA and DHA into blood lipids in healthy adults: a randomised-controlled trial, Br J Nutr, 116 (2016) 788-797.

[12] J. Folch, M. Lees, G.H. Sloane Stanley, A simple method for the isolation and purification of total lipides from animal tissues, J Biol Chem, 226 (1957) 497-509.

[13] R. Pidsley, E. Zotenko, T.J. Peters, et al., Critical evaluation of the Illumina MethylationEPIC BeadChip microarray for whole-genome DNA methylation profiling, Genome Biol, 17 (2016) 208. 
[14] M.J. Aryee, A.E. Jaffe, H. Corrada-Bravo, C. et al., Minfi: a flexible and comprehensive Bioconductor package for the analysis of Infinium DNA methylation microarrays, Bioinformatics, 30 (2014) 1363-1369.

[15] J. Maksimovic, B. Phipson, A. Oshlack, A cross-package Bioconductor workflow for analysing methylation array data, F1000Res, 5 (2016) 1281.

[16] Y.A. Chen, M. Lemire, S. Choufani, et al., Discovery of cross-reactive probes and polymorphic CpGs in the Illumina Infinium HumanMethylation450 microarray, Epigenetics, 8 (2013) 203-209.

[17] J.P. Fortin, A. Labbe, M. Lemire, et al., Functional normalization of 450k methylation array data improves replication in large cancer studies, Genome Biol, 15 (2014) 503.

[18] W.E. Johnson, C. Li, A. Rabinovic, Adjusting batch effects in microarray expression data using empirical Bayes methods, Biostatistics, 8 (2007) 118-127.

[19] Y. Benjamini, Y. Hochberg, Controlling the False Discovery Rate - a Practical and Powerful Approach to Multiple Testing, J Roy Stat Soc B Met, 57 (1995) 289-300.

[20] S.P. Hoile, N.A. Irvine, C.J. Kelsall, C. et al., Maternal fat intake in rats alters 20:4n-6 and 22:6n-3 status and the epigenetic regulation of Fads2 in offspring liver, J Nutr Biochem, 24 (2013) 1213-1220.

[21] C.M. Sibbons, N.A. Irvine, J.E. Perez-Mojica, et al., Polyunsaturated Fatty Acid Biosynthesis Involving Delta 8 Desaturation and Differential DNA Methylation of FADS2 Regulates Proliferation of Human Peripheral Blood Mononuclear Cells, Front Immunol, 9 (2018) 432. [22] A.J. Stewart, S. Hannenhalli, J.B. Plotkin, Why transcription factor binding sites are ten nucleotides long, Genetics, 192 (2012) 973-985.

[23] T.L. Bailey, C. Elkan, Fitting a mixture model by expectation maximization to discover motifs in biopolymers, Proc Int Conf Intell Syst Mol Biol, 2 (1994) 28-36.

[24] S. Heinz, C. Benner, N. Spann, et al. Glass, Simple combinations of lineage-determining transcription factors prime cis-regulatory elements required for macrophage and B cell identities, Mol Cell, 38 (2010) 576-589.

[25] S. Mahony, P.E. Auron, P.V. Benos, DNA familial binding profiles made easy: Comparison of various motif alignment and clustering strategies, Plos Comput Biol, 3 (2007) 578-591.

[26] S. Mahony, P.V. Benos, STAMP: a web tool for exploring DNA-binding motif similarities, Nucleic Acids Research, 35 (2007) W253-W258.

[27] S. Gupta, J.A. Stamatoyannopoulos, T.L. Bailey, W.S. Noble, Quantifying similarity between motifs, Genome Biology, 8 (2007). 
[28] I.V. Kulakovskiy, I.E. Vorontsov, I.S. Yevshin, et al. et al, HOCOMOCO: towards a complete collection of transcription factor binding models for human and mouse via large-scale ChIP-Seq analysis, Nuc Acids Research, 46 (2018) D252-D259.

[29] W. Stoffel, Eker, H. Assad, H. Sprecher, Enzymatic studies on the mechanism of the retroconversion of C22-polyenoic fatty acids to their C20-homologues, Hoppe Seylers Z Physiol Chem, 351 (1970) 1545-1554.

[30] E. Christensen, B. Woldseth, T.A. Hagve, B.T. et al., Peroxisomal beta-oxidation of polyunsaturated long chain fatty acids in human fibroblasts. The polyunsaturated and the saturated long chain fatty acids are retroconverted by the same acyl-CoA oxidase, Scand J Clin Lab Invest Suppl, 215 (1993) 61-74.

[31] G.C. Burdge, S.A. Wootton, Conversion of alpha-linolenic acid to palmitic, palmitoleic, stearic and oleic acids in men and women, Prostaglandins Leukot.Essent.Fatty Acids, 69 (2003) 283-290. [32] S.C. Jacobsen, C. Brons, J. Bork-Jensen, et al., Effects of short-term high-fat overfeeding on genome-wide DNA methylation in the skeletal muscle of healthy young men, Diabetologia, 55 (2012) 3341-3349.

[33] C.J. Kelsall, S.P. Hoile, N.A. Irvine, et al., G.C. Burdge, Vascular dysfunction induced in offspring by maternal dietary fat involves altered arterial polyunsaturated Fatty Acid biosynthesis, PLoS One, 7 (2012) e34492.

[34] H. Arakawa, Netrin-1 and its receptors in tumorigenesis, Nature reviews. Cancer, 4 (2004) 978-987.

[35] A. Caretta, C. Mucignat-Caretta, Protein kinase a in cancer, Cancers (Basel), 3 (2011) 913-926. [36] M. Newell, K. Baker, L.M. Postovit, C.J. Field, A Critical Review on the Effect of Docosahexaenoic Acid (DHA) on Cancer Cell Cycle Progression, International journal of molecular sciences, 18 (2017).

[37] R. Rangel-Salazar, M. Wickstrom-Lindholm, C.A. Aguilar-Salinas, et al., Human native lipoprotein-induced de novo DNA methylation is associated with repression of inflammatory genes in THP-1 macrophages, BMC genomics, 12 (2011) 582.

[38] M. Okano, D.W. Bell, D.A. Haber, E. Li, DNA methyltransferases Dnmt3a and Dnmt3b are essential for de novo methylation and mammalian development, Cell, 99 (1999) 247-257.

[39] S. Ito, A.C. D'Alessio, O.V. Taranova, K. Hong, L.C. Sowers, Y. Zhang, Role of Tet proteins in $5 \mathrm{mC}$ to $5 \mathrm{hmC}$ conversion, ES-cell self-renewal and inner cell mass specification, Nature, 466 (2010) 1129-1133.

[40] M. Tahiliani, K.P. Koh, Y. Shen, et al., Conversion of 5-methylcytosine to 5hydroxymethylcytosine in mammalian DNA by MLL partner TET1, Science, 324 (2009) 930-935. 
[41] V. Ceccarelli, V. Valentini, S. Ronchetti, et al., Vecchini, Eicosapentaenoic acid induces DNA demethylation in carcinoma cells through a TET1-dependent mechanism, FASEB J, (2018) fj201800245R.

[42] S.K. Bhattacharya, S. Ramchandani, N. Cervoni, M. Szyf, A mammalian protein with specific demethylase activity for mCpG DNA, Nature, 397 (1999) 579-583.

[43] B. Zhu, Y. Zheng, H. Angliker, et al., 5-Methylcytosine DNA glycosylase activity is also present in the human MBD4 (G/T mismatch glycosylase) and in a related avian sequence, Nucleic Acids Res, 28 (2000) 4157-4165.

[44] G. Barreto, A. Schafer, J. Marhold, et al., Gadd45a promotes epigenetic gene activation by repair-mediated DNA demethylation, Nature, 445 (2007) 671-675.

[45] J.P. Jost, Nuclear Extracts of Chicken Embryos Promote An Active Demethylation of Dna by Excision Repair of 5-Methyldeoxycytidine, Proc Natl Acad Sci USA, 90 (1993) 4684-4688.

[46] F. Bian, X. Ma, S.D. Villivalam, et al. TET2 facilitates PPARgamma agonist-mediated gene regulation and insulin sensitization in adipocytes, Metabolism, 89 (2018) 39-47.

[47] Y. Luo, C. Xie, C.N. Brocker, et al., Intestinal PPARalpha Protects Against Colon Carcinogenesis via Regulation of Methyltransferases DNMT1 and PRMT6, Gastroenterology, 157 (2019) 744-759 e744.

[48] N.O. Hudson, B.A. Buck-Koehntop, Zinc Finger Readers of Methylated DNA, Molecules, 23 (2018).

[49] Y. Wang, M. Xiao, X. Chen, et al., WT1 recruits TET2 to regulate its target gene expression and suppress leukemia cell proliferation, Mol Cell, 57 (2015) 662-673.

[50] P.O. Esteve, H.G. Chin, S. Pradhan, Molecular mechanisms of transactivation and doxorubicin-mediated repression of survivin gene in cancer cells, Journal of Biological Chemistry, 282 (2007) 2615-2625.

[51] R. Clarke-Harris, T.J. Wilkin, J. Hosking, et al., Peroxisomal proliferator activated receptorgamma-co-activator-1alpha promoter methylation in blood at 5-7 years predicts adiposity from 9 to 14 years (EarlyBird 50), Diabetes, (2014).

[52] K.M. Godfrey, A. Sheppard, P.D. Gluckman, et al., Epigenetic gene promoter methylation at birth is associated with child's later adiposity, Diabetes, 60 (2011) 1528-1534.

[53] K. Lillycrop, R. Murray, C. Cheong, et al., ANRIL Promoter DNA Methylation: A Perinatal Marker for Later Adiposity, EBioMedicine, 19 (2017) 60-72.

[54] R. Murray, J. Bryant, P. Titcombe, et al., DNA methylation at birth within the promoter of ANRIL predicts markers of cardiovascular risk at 9 years, Clin Epigenetics, 8 (2016) 90. 
Table 1. PCR and Pyrosequencing primers

\begin{tabular}{llll}
\hline $850 \mathrm{~K}$ CpG & Primer Sequences & Temp $^{\mathrm{a}}$ & Size $^{\mathrm{b}}$ \\
ID & $\left(5^{\prime}-3^{\prime}\right)$ & $\left({ }^{\circ} \mathrm{C}\right)$ & $(\mathrm{bp})$ \\
\hline \hline
\end{tabular}

\begin{tabular}{|c|c|c|c|}
\hline & Fwd TGTATATATTTGATAGGAGGGAAAGT & & \\
\hline \multirow[t]{3}{*}{$\operatorname{cg} 26292058$} & Rev BIO-ACACCCCTTAАAАTCATCCTATATATTAC & 57 & 162 \\
\hline & Seq TTTAAGGTGTGTGTTAGA & & \\
\hline & Fwd GTGTTTTTTGAGAGGAAATGGGTGATAAT & & \\
\hline \multirow[t]{3}{*}{$\operatorname{cg} 05475386$} & Rev BIO-TACATTACACAAACCTTATTAAACATTACC & 57 & 121 \\
\hline & Seq GGTTTTTTAATAGAAGGA & & \\
\hline & Fwd AGGGTAAAGTTTGAGGGTATTTGT & & \\
\hline \multirow[t]{3}{*}{$\operatorname{cg} 27188282$} & Rev BIO-АТСТTCТTCССААААСАТСТТСТС & 62 & 165 \\
\hline & Seq TGTTTTTGTGATTTAATTTATTATTTAAG & & \\
\hline & Fwd BIO-TTAGGTAGATGGGGGAGTTGG & & \\
\hline \multirow[t]{3}{*}{$\operatorname{cg} 06989443$} & Rev ACAAACAAACAAATAATTCCCCCTTACA & 57 & 246 \\
\hline & Seq CTAAAAACAACTATTTATTCCCT & & \\
\hline & Fwd BIO-TTTTGTTATTATTTAGATTGTGGTTTGG & & \\
\hline \multirow[t]{2}{*}{$\operatorname{cg} 22518417$} & Rev ACCCAАCCTTCTAАТCTTTTCATAA & 57 & 79 \\
\hline & Seq AAAAAACATTAATACTTATATACT & & \\
\hline
\end{tabular}

Fwd, forward primer; Rev, reverse primer; Seq, sequencing primer; BIO-, biotin-labeled primer.

${ }^{\mathrm{a} A n n e a l i n g ~ t e m p e r a t u r e ;}{ }^{\mathrm{b}}$ Amplicon size. 
Table 2. Top ten canonical pathways enriched for differentially methylated genes.

\begin{tabular}{|c|c|c|c|c|}
\hline \multirow[b]{3}{*}{ IPA ${ }^{\circledR}$ Canonical Pathways } & \multirow[b]{3}{*}{$\mathrm{P}$} & \multicolumn{2}{|c|}{$\begin{array}{l}\text { Number of } \\
\text { differentially } \\
\text { methylated loci }\end{array}$} & \multirow{3}{*}{$\begin{array}{l}\text { Number of } \\
\text { genes }\end{array}$} \\
\hline & & \multicolumn{2}{|c|}{ Methylation change } & \\
\hline & & Increased & Decreased & \\
\hline Pathways altered by incubation with $22: 6 n-3$ & & & & \\
\hline Synaptic Long-Term Potentiation & $<0.0001$ & 7 & 12 & 17 \\
\hline Synaptic Long-Term Depression & $<0.0001$ & 5 & 17 & 20 \\
\hline Protein Kinase A Signalling & 0.0001 & 12 & 29 & 34 \\
\hline Netrin Signalling & 0.0001 & 4 & 7 & 11 \\
\hline Dopamine-PPP1R1B Feedback in cAMP Signalling & 0.0002 & 8 & 10 & 18 \\
\hline GPCR-Mediated Integration of Enteroendocrine Signalling & 0.0003 & 3 & 8 & 11 \\
\hline Axonal Guidance Signalling & 0.0003 & 17 & 21 & 36 \\
\hline G Protein Signalling Mediated by Tubby & 0.0003 & 4 & 3 & 7 \\
\hline GPCR-Mediated Nutrient Sensing in Enteroendocrine Cells & 0.0003 & 4 & 10 & 14 \\
\hline Cellular Effects of Sildenafil & 0.0004 & 5 & 15 & 15 \\
\hline Pathways altered by incubation with $18: 1 \mathrm{n}-9$ & & & & \\
\hline Amyotrophic Lateral Sclerosis Signalling & 0.0005 & 4 & 4 & 8 \\
\hline Opioid Signalling Pathway & 0.0065 & 5 & 5 & 10 \\
\hline Aryl Hydrocarbon Receptor Signalling & 0.0076 & 3 & 6 & 9 \\
\hline Clathrin-mediated Endocytosis Signalling & 0.0076 & 5 & 4 & 7 \\
\hline Human Embryonic Stem Cell Pluripotency & 0.0089 & 3 & 4 & 7 \\
\hline Fc $\gamma$ Receptor IIB Signalling in B Lymphocytes & 0.0100 & 4 & 1 & 5 \\
\hline Glioma Signalling & 0.0115 & 5 & 2 & 6 \\
\hline Regulation of the Epithelial-Mesenchymal Transition & 0.0129 & 4 & 4 & 8 \\
\hline Retinoate Biosynthesis I & 0.0145 & 2 & 1 & 3 \\
\hline Pigment Epithelium-derived Factor (PEDF) Signalling & 0.0145 & 3 & 2 & 5 \\
\hline
\end{tabular}

P-values were calculated using Fisher's exact test for Canonical pathways function in IPA ${ }^{\circledR}$. PPP1R1B, protein phosphatase 1 Regulatory subunit 1B; cAMP, cyclic adenosine monophosphate; GPCR, g-protein-coupled receptors. 
Table 3. Putative transcription factor response elements enriched at differentially methylated $\mathrm{CpG}$ loci in Jurkat cells treated with $22: 6 n-3$ or $18: 1 n-9$.

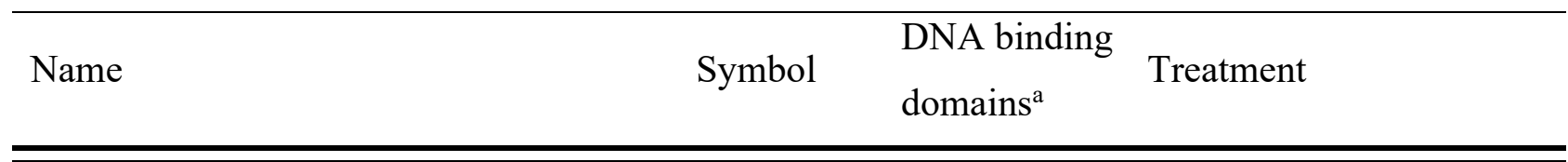

Androgen receptor

Early growth response 1

Forkhead box J3

IKAROS family zinc finger 1

Kruppel-like factor 1

Kruppel-like factor 3

Kruppel-like factor 15

Kruppel-like factor 15

MYC associated zinc finger protein

POZ/BTB and AT hook containing zinc

finger 1

PR/SET domain 6

Sp1 transcription factor

Sp2 transcription factor

Sp3 transcription factor

Sp4 transcription factor

Sex determining region $\mathrm{Y}$

TATA-box binding protein associated factor 1

Upstream transcription factor 2, C-fos interacting

Vascular endothelial zinc finger 1

Wilms tumour 1

Zinc finger and BTB domain containing 17

Zinc finger protein 250

Zinc finger protein 263

Zinc finger protein 281

Zinc finger protein 341

AR ZF-C4 22:6n-3

EGR1 ZF-C2H2 22:6n-3 ${ }^{b}$

FOXJ3 Fork-head 22:6n-3

IKZF1 ZF-C2H2 22:6n-3

KLF1 ZF-C2H2 22:6n-3 ${ }^{b}$

KLF3 ZF-C2H2 22:6n- $3^{a}$ and $18: 1 n-9^{a}$

KLF9 ZF-C2H2 18:1n-9d

KLF15 ZF-C2H2 22:6n- $3^{a}$ and $18: 1 n-9^{d}$

MAZ ZF-C2H2 22:6n-3 $3^{\mathrm{ab}}$ and 18:1n-9

PATZ1 A.T. hook, 22:6n- $3^{\text {ab }}$ and 18:1n-9 $\mathrm{ZF}-\mathrm{C} 2 \mathrm{H} 2$

PRDM6 ZF-C2H2 22:6n-3 ${ }^{\mathrm{c}}$

SP1 ZF-C2H2 22:6n-3 ${ }^{a b}$ and $18: 1 n-9^{a}$

SP2 ZF-C2H2 22:6n-3 $3^{\text {ab }}$ and 18:1n-9

SP3 ZF-C2H2 22:6n-3 $3^{\text {ab }}$ and $18: 1 n-9^{a b}$

SP4 ZF-C2H2 22:6n-3

SRY HMG box 22:6n-3

TAF1 HMG box $22: 6 n-3^{a}$

USF2

bHLH and LZ

$18: 1 n-9^{a}$

VEZF1 ZF-C2H2 22:6n- $3^{\mathrm{ab}}$ and $18: 1 \mathrm{n}-9^{\mathrm{d}}$

WT1 ZF-C2H2 22:6n- $3^{\mathrm{b}}$ and $18: 1 \mathrm{n}-9^{\mathrm{ab}}$

ZBT17 ZF-C2H2 22:6n-3

ZN250 ZF-C2H2 22:6n-3 ${ }^{\text {bd }}$

ZN263 ZF-C2H2 22:6n-3

ZN281 ZF-C2H2 22:6n-3 and $18: 1 n-9^{a}$

ZN341 ZF-C2H2 22:6n- $3^{a}$ and 18:1n-9 
Superscripts indicate that alignment was identified using differentially methylated DNA sequences in ${ }^{\mathrm{a}}$, any genomic region; ${ }^{\mathrm{b}}$, intergenic regions; ${ }^{\mathrm{c}}$, promoter regions; or ${ }^{\mathrm{d}}$, gene body regions. ZF-C4, zinc finger type Cys4; ZF-C2H2, zinc finger type Cys2-His2; A.T. hook, adenine-thymine hook; HMG box, high mobility group box; bHLH, basic helix-loop-helix; L-Z,

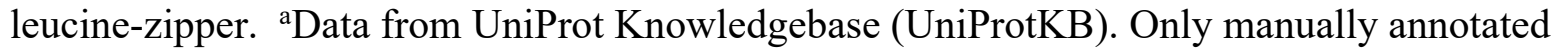
records extracted from literature with further computational analysis were used. 


\section{2:6n-3}

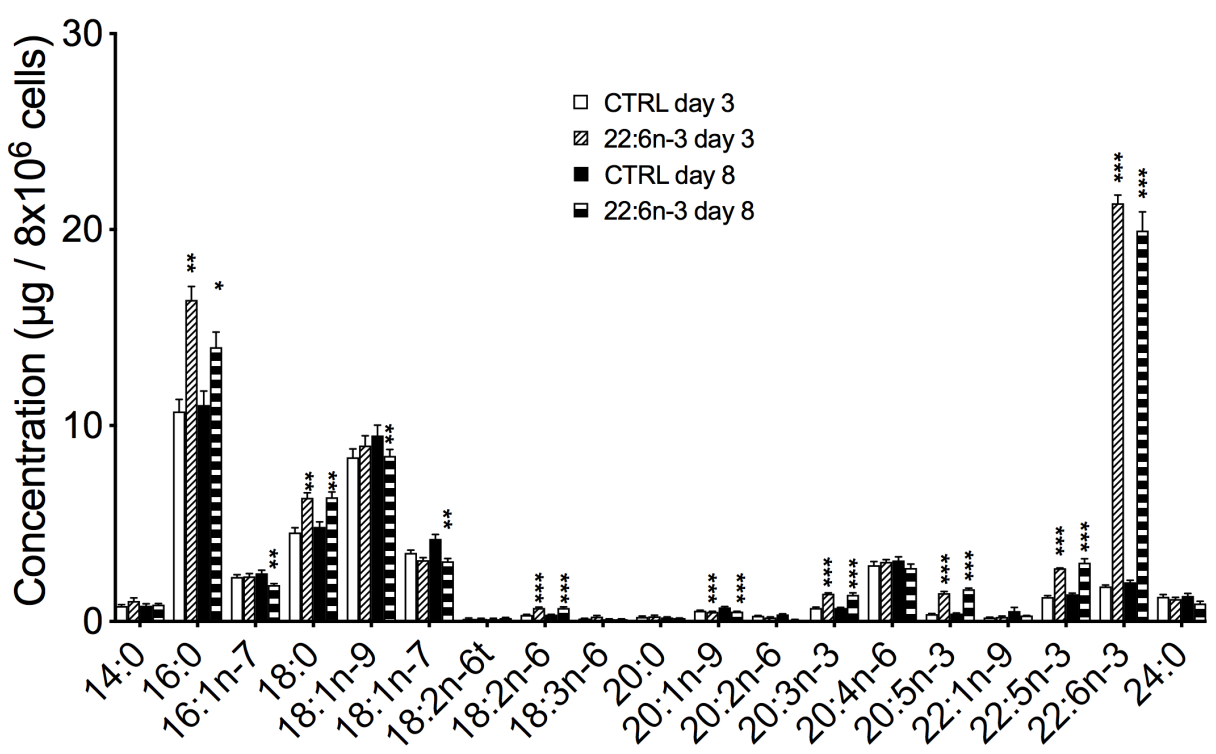

Fatty acids

$18: 1 n-9$

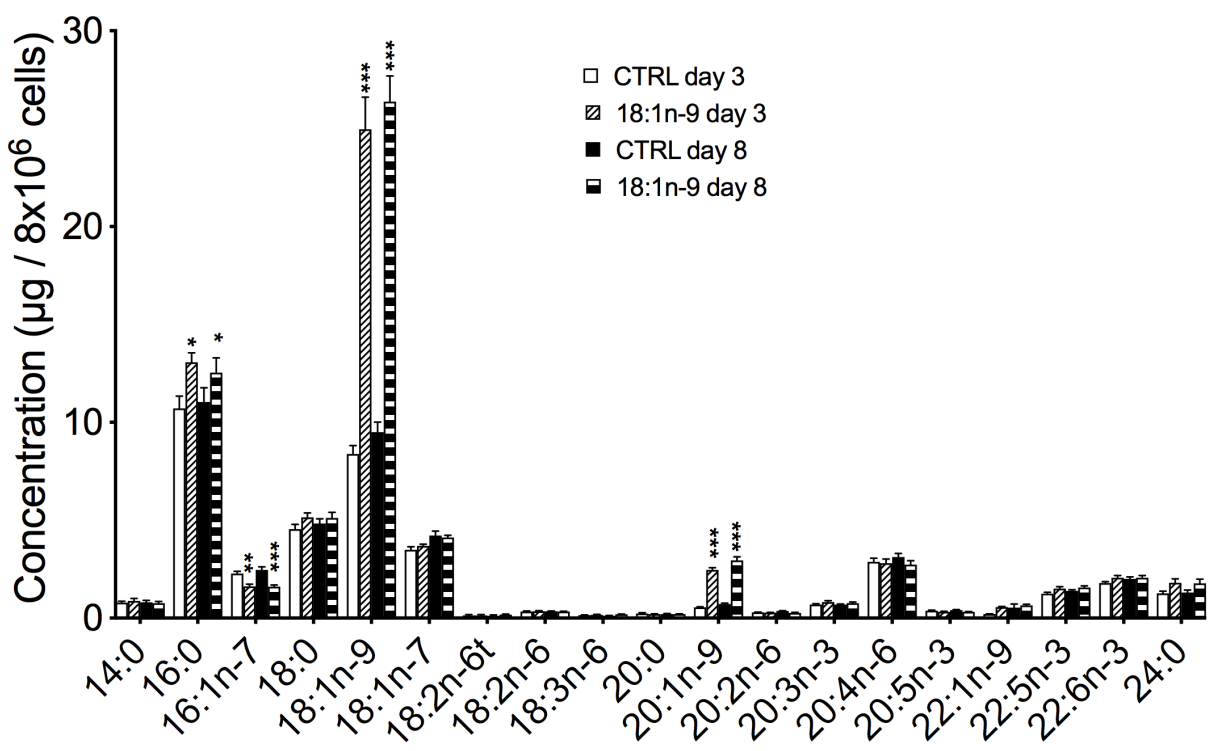

Fatty acids

Figure 1. Fatty acid composition of Jurkat cells before and after treatment for 3 ( $n=4$ replicate cultures) or 8 days ( $n=7$ replicate cultures) with $15 \mu \mathrm{M}$ either $22: 6 n-3$ or 18:1n-9. Data are mean \pm standard error of the mean. Control versus treatment means at each time point were compared by Student's unpaired t-test. Means that differed significantly between cells treated with $22: 6 n-3$ or 18:1n-9 are indicated by $* \mathrm{P}<0.05, * * \mathrm{P}<0.01$ and $* * * \mathrm{P}<0.001$. 
A

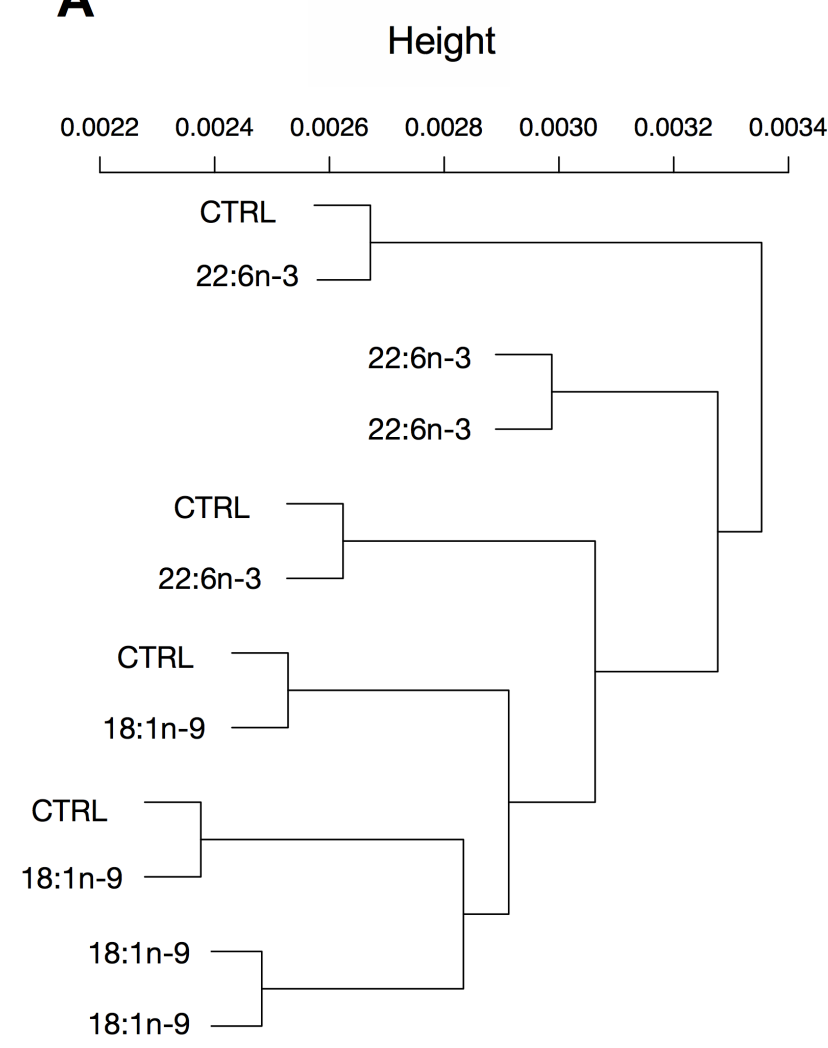

B

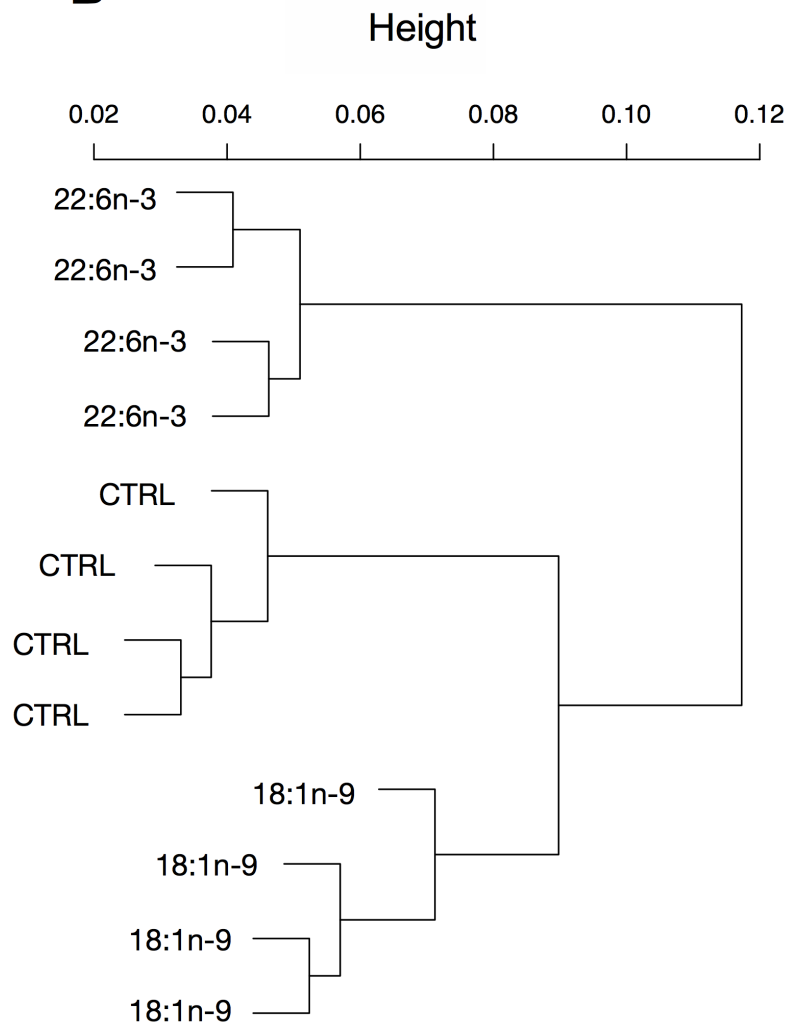

Figure 2. Cluster dendrogram of samples ( $n=4$ culture replicates per treatment). (A) Unsupervised clustering of M-values of all $\mathrm{CpG}$ loci analysed in the $850 \mathrm{~K}$ array. (B) Unsupervised clustering of M-values of differentially methylated $\mathrm{CpG}$ loci only. 


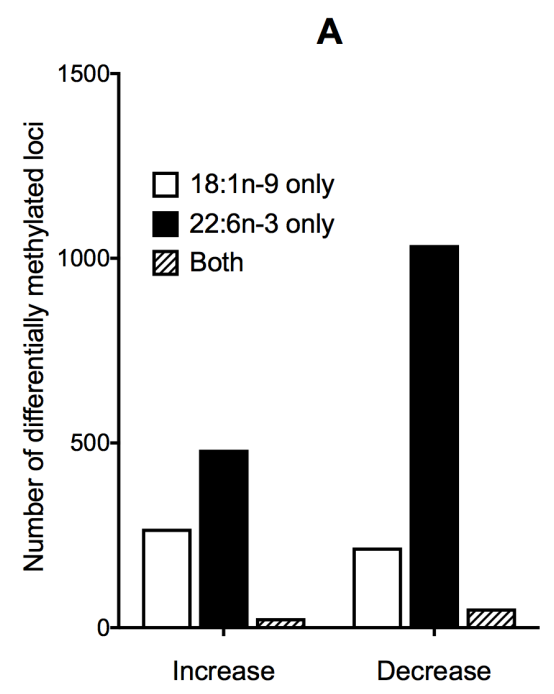

B
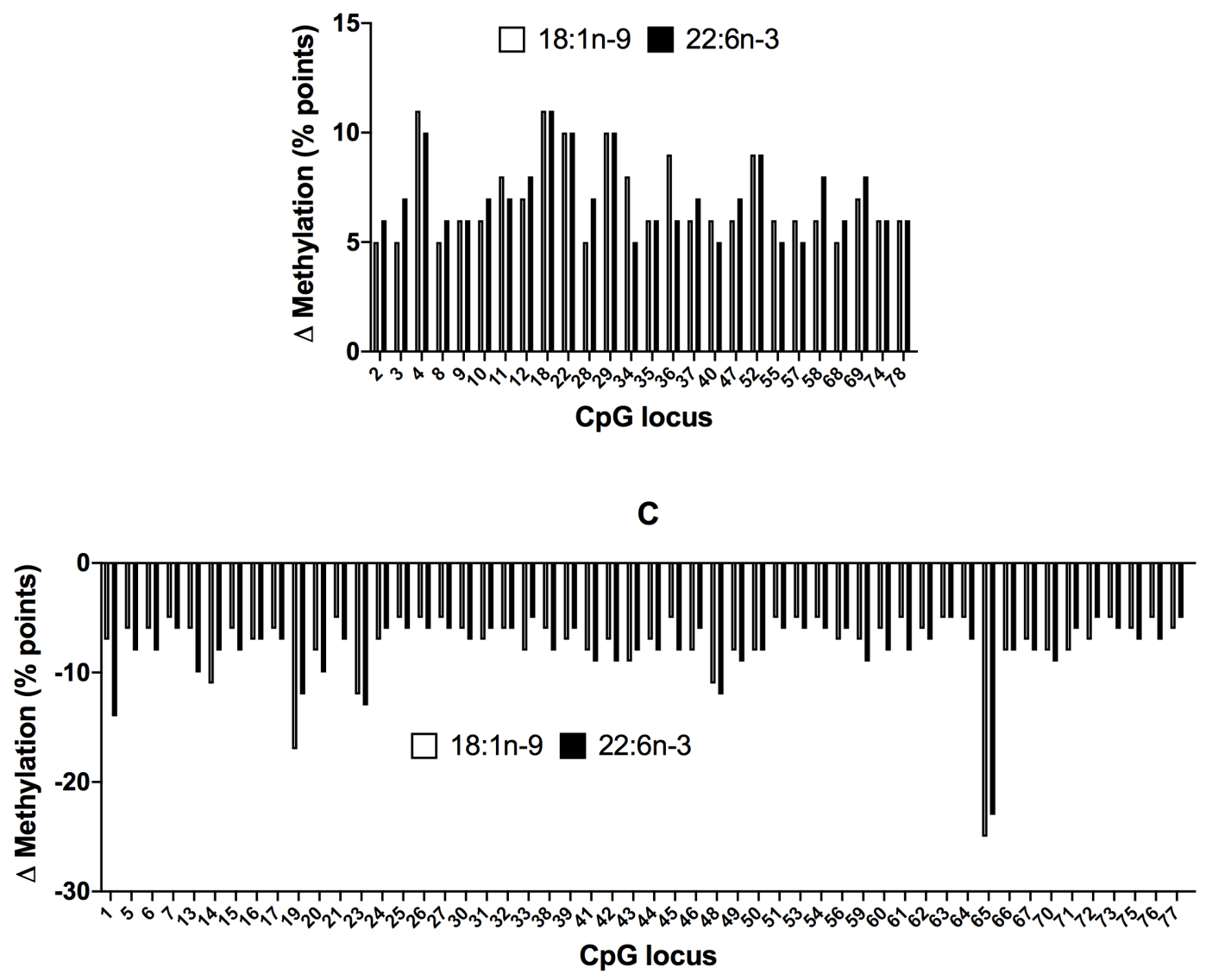

Figure 3. Number and direction of change of differentially methylated $\mathrm{CpG}$ loci after treatment with $22: 6 n-3$ or $18: 1 n-9$ for 8 days. (A) Total number of differentially methylated CpG loci. (B) Change in methylation of loci hypermethylated compared to vehicle control by 22:6n-3 or 18:1n-9. (C) Change in methylation of loci hypomethylated compared to vehicle control by $22: 6 n-3$ or 18:1n-9. The chromosome locations of the differentially methylated $\mathrm{CpG}$ loci are shown in Supplemental Table 2 . 

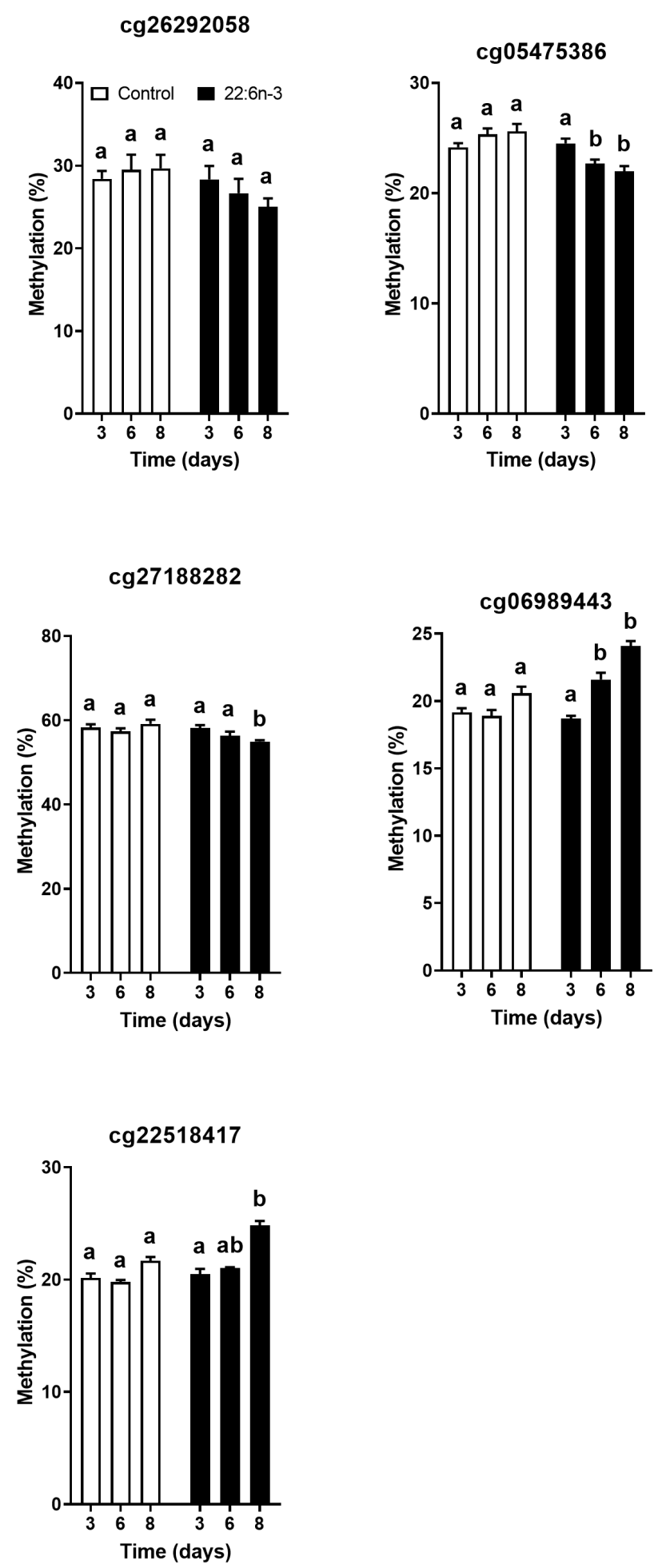

Fig. 4. Methylation status of candidate $\mathrm{CpG}$ loci after $3(\mathrm{n}=8), 6(\mathrm{n}=8)$ and $8(\mathrm{n}=6)$ days incubation with 22:6n-3. Data are shown as means \pm SEM. Statistical comparisons were by twoway ANOVA with Tukey post-hoc test. Means that differed significantly $(\mathrm{P}<0.05)$ between timepoints are indicated by different letters. 
cg26292058

cg05475386

$\operatorname{cg} 27188282$
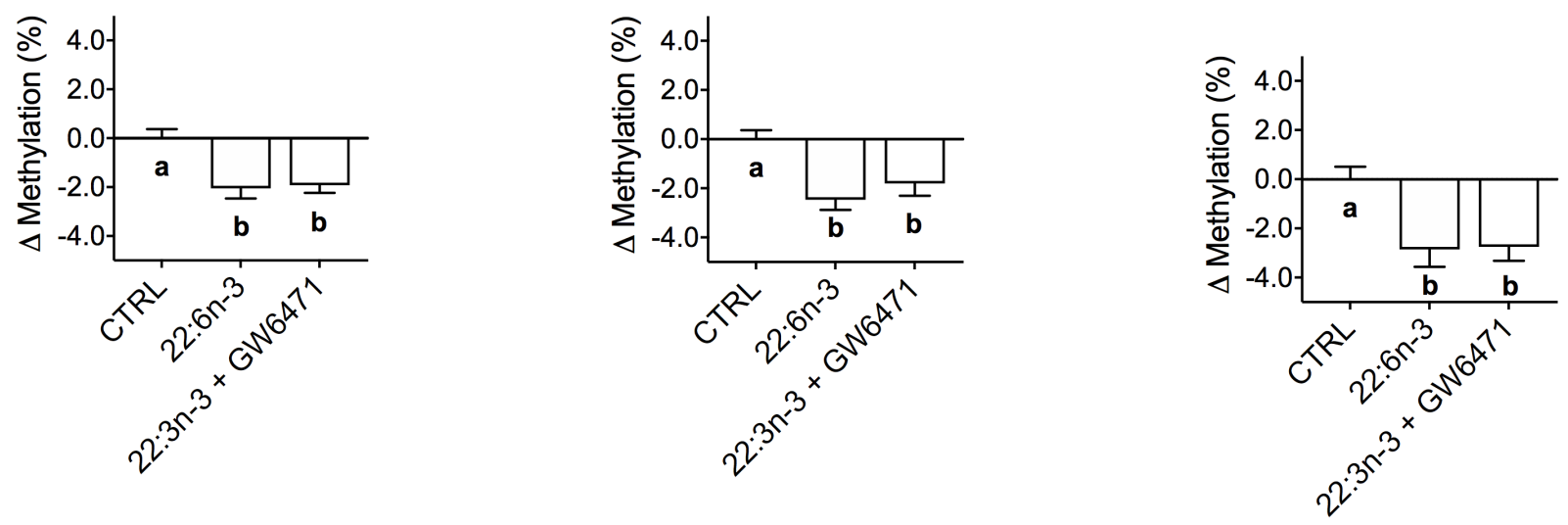

cg06989443

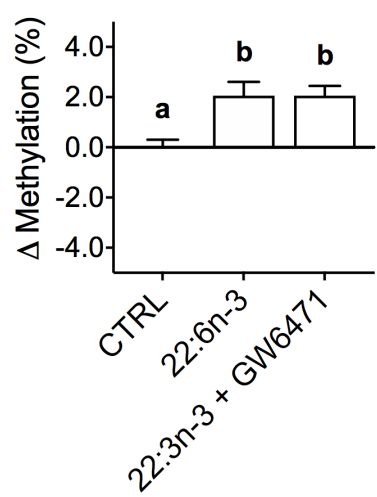

$\operatorname{cg} 22518417$

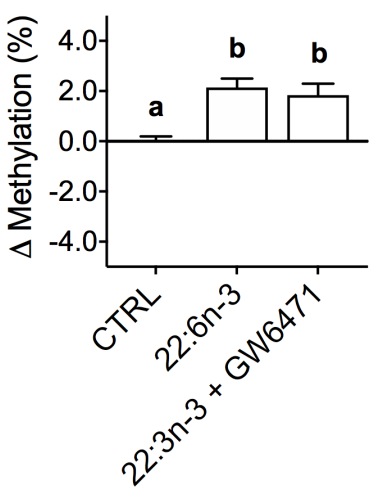

Fig. 5. The effect of the PPAR $\alpha$ antagonist GW6471 on the induction of altered DNA methylation of 5 candidate $\mathrm{CpG}$ loci by 22:6n-3. Values are mean \pm SEM change in DNA methylation after incubation for 8 days with either vehicle (CTRL, control) or 22:6n-3 alone, or 22:6n-3 plus GW6471. CpG loci are indicated by their chromosome locations. Means were compared by 1-way ANOVA with Tukey's post hoc test for multiple comparisons. Means which differed significantly $(\mathrm{P}<0.05)$ are indicated by different letters. 
Docosahexaenoic acid and oleic acid induce altered DNA methylation of individual CpG loci in Jurkat T cells

Supplemental Table 1. DNA methylation of CpG loci that were altered by 22:6n-3 and 18:1n-9.

\begin{tabular}{|c|c|c|c|c|c|c|c|c|c|}
\hline $\begin{array}{c}\mathrm{CpG} \\
\text { Number }\end{array}$ & IlmnID & Chr & Chr Position & Strand & $\mathrm{CpGi}$ & Gene & $\begin{array}{l}\text { Gene } \\
\text { Region }\end{array}$ & $22: 6 \mathrm{n}-3(\Delta \%$ pts $)$ & $18: 1 \mathrm{n}-9(\Delta \%$ pts $)$ \\
\hline 1 & $\operatorname{cg} 26292058$ & 1 & 192544252 & - & OpenSea & RGS1 & TSS1500 & $-14.0 \%$ & $-7.0 \%$ \\
\hline 2 & $\operatorname{cg} 23243552$ & 1 & 98500398 & - & OpenSea & MIR137HG & Body & $6.0 \%$ & $5.0 \%$ \\
\hline 3 & $\operatorname{cg} 17002156$ & 1 & 183995878 & + & OpenSea & GLT25D2 & Body & $7.0 \%$ & $5.0 \%$ \\
\hline 4 & $\operatorname{cg} 17291907$ & 1 & 47010131 & + & Island & no gene & no gene & $10.0 \%$ & $11.0 \%$ \\
\hline 5 & $\operatorname{cg} 24042978$ & 2 & 167344458 & - & OpenSea & SCN7A & TSS1500 & $-8.0 \%$ & $-6.0 \%$ \\
\hline 6 & $\operatorname{cg} 27301645$ & 2 & 88667670 & + & OpenSea & no gene & no gene & $-8.0 \%$ & $-6.0 \%$ \\
\hline 7 & $\operatorname{cg} 14383480$ & 2 & 168043663 & - & OpenSea & XIRP2 & Body & $-6.0 \%$ & $-5.0 \%$ \\
\hline 8 & $\operatorname{cg} 15355298$ & 2 & 48011201 & - & Island & MSH6 & Body & $6.0 \%$ & $5.0 \%$ \\
\hline 9 & $\operatorname{cg} 18946478$ & 2 & 20866414 & - & Island & GDF7 & TSS200 & $6.0 \%$ & $6.0 \%$ \\
\hline 10 & $\operatorname{cg} 24203562$ & 2 & 239241869 & + & OpenSea & TRAF3IP1 & Body & $7.0 \%$ & $6.0 \%$ \\
\hline 11 & $\operatorname{cg} 26001287$ & 2 & 111877753 & - & Island & BCL2L11 & TSS1500 & $7.0 \%$ & $8.0 \%$ \\
\hline 12 & ch.2.252555R* & 2 & 9381833 & + & OpenSea & ASAP2 & Body & $8.0 \%$ & $7.0 \%$ \\
\hline 13 & $\operatorname{cg} 17420463$ & 3 & 185046594 & - & OpenSea & MAP3K13 & $\mathrm{NC}$ & $-10.0 \%$ & $-6.0 \%$ \\
\hline 14 & $\operatorname{cg} 15237829$ & 3 & 171102373 & + & OpenSea & TNIK & Body & $-8.0 \%$ & $-11.0 \%$ \\
\hline 15 & $\operatorname{cg} 05401575$ & 3 & 63428587 & - & OpenSea & SYNPR & $\mathrm{NC}$ & $-8.0 \%$ & $-6.0 \%$ \\
\hline
\end{tabular}




\begin{tabular}{|c|c|c|c|c|c|c|c|c|c|}
\hline 16 & $\operatorname{cg} 21195620$ & 3 & 15838030 & - & OpenSea & ANKRD28 & $\mathrm{NC}$ & $-7.0 \%$ & $-7.0 \%$ \\
\hline 17 & $\operatorname{cg} 12405098$ & 3 & 178275369 & - & OpenSea & KCNMB2 & $\mathrm{NC}$ & $-7.0 \%$ & $-6.0 \%$ \\
\hline 18 & $\operatorname{cg} 04730456$ & 3 & 122510658 & - & N_Shore & HSPBAP1 & Body & $11.0 \%$ & $11.0 \%$ \\
\hline 19 & $\operatorname{cg} 10841253$ & 4 & 10531768 & + & OpenSea & CLNK & Body & $-12.0 \%$ & $-17.0 \%$ \\
\hline 20 & $\operatorname{cg} 07321467$ & 4 & 81960704 & - & OpenSea & BMP3 & Body & $-10.0 \%$ & $-8.0 \%$ \\
\hline 21 & $\operatorname{cg} 07815324$ & 4 & 43135729 & - & OpenSea & no gene & no gene & $-7.0 \%$ & $-5.0 \%$ \\
\hline 22 & $\operatorname{cg} 17089062$ & 4 & 174427773 & - & N_Shore & no gene & no gene & $10.0 \%$ & $10.0 \%$ \\
\hline 23 & $\operatorname{cg} 04574083$ & 5 & 6765204 & - & OpenSea & no gene & no gene & $-13.0 \%$ & $-12.0 \%$ \\
\hline 24 & $\operatorname{cg} 03701805$ & 5 & 122452418 & + & OpenSea & PRDM6 & Body & $-6.0 \%$ & $-7.0 \%$ \\
\hline 25 & $\operatorname{cg} 19508967$ & 5 & 1840347 & + & OpenSea & no gene & no gene & $-6.0 \%$ & $-5.0 \%$ \\
\hline 26 & $\operatorname{cg} 03570708$ & 5 & 133135701 & + & OpenSea & no gene & no gene & $-6.0 \%$ & $-5.0 \%$ \\
\hline 27 & $\operatorname{cg} 18052369$ & 5 & 99970791 & + & OpenSea & no gene & no gene & $-6.0 \%$ & $-5.0 \%$ \\
\hline 28 & $\operatorname{cg} 26092471$ & 5 & 174150712 & + & N_Shore & MSX2 & TSS 1500 & $7.0 \%$ & $5.0 \%$ \\
\hline 29 & $\operatorname{cg} 00417638$ & 5 & 5586070 & - & OpenSea & no gene & no gene & $10.0 \%$ & $10.0 \%$ \\
\hline 30 & $\operatorname{cg} 13396038$ & 6 & 141766970 & - & OpenSea & no gene & no gene & $-7.0 \%$ & $-6.0 \%$ \\
\hline 31 & $\operatorname{cg} 09160330$ & 6 & 46760919 & - & OpenSea & MEP1A & TSS200 & $-6.0 \%$ & $-7.0 \%$ \\
\hline 32 & $\operatorname{cg} 15416661$ & 6 & 28725789 & - & OpenSea & no gene & no gene & $-6.0 \%$ & $-6.0 \%$ \\
\hline 33 & $\operatorname{cg} 27639249$ & 6 & 30016420 & + & OpenSea & NCRNA00171 & Body & $-5.0 \%$ & $-8.0 \%$ \\
\hline 34 & $\operatorname{cg} 05938671$ & 6 & 125421084 & - & Island & no gene & no gene & $5.0 \%$ & $8.0 \%$ \\
\hline 35 & $\operatorname{cg} 22170402$ & 6 & 76553236 & + & OpenSea & MYO6 & Body & $6.0 \%$ & $6.0 \%$ \\
\hline 36 & $\operatorname{cg} 06423354$ & 6 & 30165652 & + & OpenSea & TRIM26 & Body & $6.0 \%$ & $9.0 \%$ \\
\hline 37 & $\operatorname{cg} 08760395$ & 6 & 53275751 & + & OpenSea & no gene & no gene & $7.0 \%$ & $6.0 \%$ \\
\hline 38 & $\operatorname{cg} 19878120$ & 7 & 105655497 & - & OpenSea & CDHR3 & Body & $-8.0 \%$ & $-6.0 \%$ \\
\hline
\end{tabular}




\begin{tabular}{|c|c|c|c|c|c|c|c|c|c|}
\hline 39 & $\operatorname{cg} 00226689$ & 7 & 41259421 & - & OpenSea & no gene & no gene & $-6.0 \%$ & $-7.0 \%$ \\
\hline 40 & $\operatorname{cg} 24471726$ & 7 & 90872375 & + & OpenSea & no gene & no gene & $5.0 \%$ & $6.0 \%$ \\
\hline 41 & $\operatorname{cg} 21548021$ & 8 & 15873055 & + & OpenSea & no gene & no gene & $-9.0 \%$ & $-8.0 \%$ \\
\hline 42 & $\operatorname{cg} 00947236$ & 8 & 29020165 & + & OpenSea & KIF13B & Body & $-9.0 \%$ & $-7.0 \%$ \\
\hline 43 & $\operatorname{cg} 08997191$ & 8 & 133788834 & - & S_Shore & PHF20L1 & 5'UTR & $-8.0 \%$ & $-9.0 \%$ \\
\hline 44 & $\operatorname{cg} 23019611$ & 8 & 23458336 & - & OpenSea & no gene & no gene & $-8.0 \%$ & $-7.0 \%$ \\
\hline 45 & $\operatorname{cg} 00659910$ & 8 & 64617139 & - & OpenSea & no gene & no gene & $-8.0 \%$ & $-5.0 \%$ \\
\hline 46 & $\operatorname{cg} 15423200$ & 8 & 52589863 & - & OpenSea & PXDNL & Body & $-6.0 \%$ & $-8.0 \%$ \\
\hline 47 & $\operatorname{cg} 16467757$ & 8 & 95888145 & + & OpenSea & INTS8 & Body & $7.0 \%$ & $6.0 \%$ \\
\hline 48 & $\operatorname{cg} 05147200$ & 9 & 22446830 & - & Island & DMRTA1 & TSS200 & $-12.0 \%$ & $-11.0 \%$ \\
\hline 49 & $\operatorname{cg} 00550721$ & 9 & 21986062 & + & N_Shelf & CDKN2A & Body & $-9.0 \%$ & $-8.0 \%$ \\
\hline 50 & $\operatorname{cg} 06819082$ & 9 & 16726627 & - & N_Shore & $\mathrm{BNC} 2$ & Body & $-8.0 \%$ & $-8.0 \%$ \\
\hline 51 & $\operatorname{cg} 01266362$ & 9 & 98265802 & - & N_Shelf & PTCH1 & 5'UTR & $-6.0 \%$ & $-5.0 \%$ \\
\hline 52 & $\operatorname{cg} 05211356$ & 9 & 19408000 & + & N_Shore & ACER2 & TSS1500 & $9.0 \%$ & $9.0 \%$ \\
\hline 53 & $\operatorname{cg} 11122255$ & 10 & 24995583 & + & OpenSea & ARHGAP21 & Body & $-6.0 \%$ & $-5.0 \%$ \\
\hline 54 & $\operatorname{cg} 11195065$ & 10 & 119292371 & + & N_Shore & EMX2OS & Body & $-6.0 \%$ & $-5.0 \%$ \\
\hline 55 & $\operatorname{cg} 23758453$ & 10 & 48952010 & + & N_Shore & $\mathrm{NC}$ & $\mathrm{NC}$ & $5.0 \%$ & $6.0 \%$ \\
\hline 56 & $\operatorname{cg} 08531298$ & 11 & 15515888 & - & OpenSea & no gene & no gene & $-6.0 \%$ & $-7.0 \%$ \\
\hline 57 & $\operatorname{cg} 09721595$ & 11 & 77773924 & - & OpenSea & THRSP & TSS1500 & $5.0 \%$ & $6.0 \%$ \\
\hline 58 & $\operatorname{cg} 10452423$ & 11 & 116424360 & + & OpenSea & no gene & no gene & $8.0 \%$ & $6.0 \%$ \\
\hline 59 & $\operatorname{cg} 09746078$ & 12 & 56966920 & - & OpenSea & RBMS2 & Body & $-9.0 \%$ & $-7.0 \%$ \\
\hline 60 & $\operatorname{cg} 24907862$ & 12 & 26112480 & - & OpenSea & RASSF8 & 5'UTR & $-8.0 \%$ & $-6.0 \%$ \\
\hline 61 & $\operatorname{cg} 07037583$ & 12 & 72452357 & + & OpenSea & no gene & no gene & $-8.0 \%$ & $-5.0 \%$ \\
\hline
\end{tabular}




\begin{tabular}{|c|c|c|c|c|c|c|c|c|c|}
\hline 62 & $\operatorname{cg} 19366091$ & 12 & 44292779 & + & OpenSea & TMEM117 & Body & $-7.0 \%$ & $-6.0 \%$ \\
\hline 63 & $\operatorname{cg} 03530940$ & 12 & 2198113 & - & OpenSea & CACNA1C & Body & $-5.0 \%$ & $-5.0 \%$ \\
\hline 64 & $\operatorname{cg} 14375976$ & 13 & 29098268 & + & OpenSea & no gene & no gene & $-7.0 \%$ & $-5.0 \%$ \\
\hline 65 & $\operatorname{cg} 02401415$ & 14 & 22968476 & + & OpenSea & no gene & no gene & $-23.0 \%$ & $-25.0 \%$ \\
\hline 66 & $\operatorname{cg} 26463402$ & 14 & 74003851 & + & N_Shore & HEATR4 & 5'UTR & $-8.0 \%$ & $-8.0 \%$ \\
\hline 67 & $\operatorname{cg} 03644541$ & 14 & 35157273 & + & OpenSea & no gene & no gene & $-8.0 \%$ & $-7.0 \%$ \\
\hline 68 & $\operatorname{cg} 02498946$ & 14 & 35907902 & - & OpenSea & no gene & no gene & $6.0 \%$ & $5.0 \%$ \\
\hline 69 & $\operatorname{cg} 16908234$ & 16 & 46835765 & + & OpenSea & no gene & no gene & $8.0 \%$ & $7.0 \%$ \\
\hline 70 & $\operatorname{cg} 03687953$ & 17 & 40834511 & - & N_Shore & $\mathrm{NC}$ & $\mathrm{NC}$ & $-9.0 \%$ & $-8.0 \%$ \\
\hline 71 & $\operatorname{cg} 22371052$ & 18 & 72021321 & + & OpenSea & C18orf63 & Body & $-6.0 \%$ & $-8.0 \%$ \\
\hline 72 & $\operatorname{cg} 22542489$ & 21 & 19616644 & - & N_Shore & CHODL & 5'UTR & $-5.0 \%$ & $-7.0 \%$ \\
\hline 73 & $\operatorname{cg} 17016559$ & 22 & 46067508 & + & Island & ATXN10 & TSS200 & $-6.0 \%$ & $-5.0 \%$ \\
\hline 74 & $\operatorname{cg} 15383187$ & 22 & 31344805 & + & OpenSea & MORC2 & Body & $6.0 \%$ & $6.0 \%$ \\
\hline 75 & cg20972857 & $\mathrm{X}$ & 47468321 & + & OpenSea & SYN1 & Body & $-7.0 \%$ & $-6.0 \%$ \\
\hline 76 & $\operatorname{cg} 23067676$ & $\mathrm{X}$ & 40141241 & - & OpenSea & LOC 101927476 & Body & $-7.0 \%$ & $-5.0 \%$ \\
\hline 77 & $\operatorname{cg} 12705389$ & $\mathrm{X}$ & 137794264 & + & S_Shore & FGF13 & Body & $-5.0 \%$ & $-6.0 \%$ \\
\hline 78 & $\operatorname{cg} 27515272$ & $\mathrm{X}$ & 75648802 & + & Island & MAGEE1 & 1stExon & $6.0 \%$ & $6.0 \%$ \\
\hline
\end{tabular}

CpGi, location of the $\mathrm{CpG}$ relative to a $\mathrm{CpG}$ island from University of California Santa Cruz (UCSC) database (https://genome.ucsc.edu); Gene region; CpG position within the gene from UCSC database; IlmnID, unique identifier from the Illumina CG database (probe ID); NC, no consensus location; Position, chromosomal coordinates of the $\mathrm{CpG}$ from the Genome Reference Consortium Human Build 37 (GRCh37); ( $\Delta \%$ pts), change in methylation (percent points); TSS200, 0-200 bases upstream of the transcription start site (TSS); TSS1500, 200-1500 bases upstream of the TSS. Probe IDs prefixed with indicate non-CpG-targeting probes. 
Supplemental Table 2. Validation of $850 \mathrm{~K}$ array results by pyrosequencing.

\begin{tabular}{ccc}
\hline & \multicolumn{2}{c}{ Difference in methylation $(\%)$} \\
\hline IlmnID & $850 \mathrm{~K}$ Array & Pyrosequencing \\
\hline $\operatorname{cg} 26292058$ & $-15^{\mathrm{a}}$ & $-16^{* * *}$ \\
$\operatorname{cg} 05475386$ & $-13^{\mathrm{a}}$ & $-14^{* *}$ \\
$\operatorname{cg} 27188282$ & $-11^{\mathrm{a}}$ & $-7^{* *}$ \\
$\operatorname{cg} 06989443$ & $12^{\mathrm{a}}$ & $17^{* * *}$ \\
$\operatorname{cg} 22518417$ & $11^{\mathrm{a}}$ & $14^{* * *}$ \\
\hline
\end{tabular}

IlmnID, unique identifier from the Illumina CG database. CpG loci were assumed to be differentially methylated at ${ }^{\text {ap }}<0.05$ and q-value $<0.05$. For methylation levels measured by pyrosequencing data, that differed significantly different by Student's unpaired t-test are indicated by $* \mathrm{P}<0.05, * * \mathrm{P}<0.01$ or $\mathrm{P}<0.01$. 


\section{Supplemental Figure 1.}
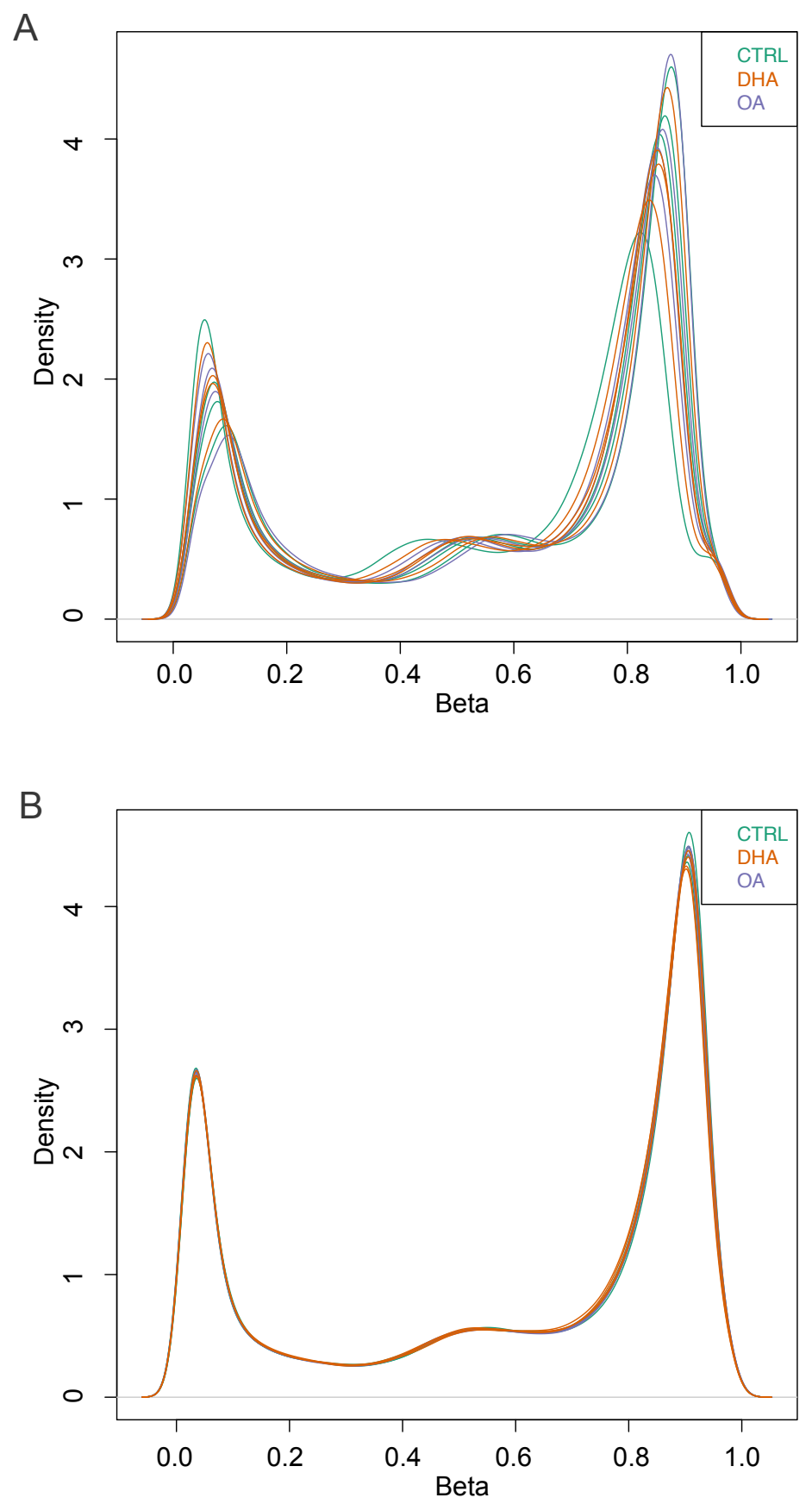

850K Array $\beta$-density distribution before (A) and after normalization (B) using Funnorm preprocessing (minfi R package). 


\section{Supplemental Figure 2.}
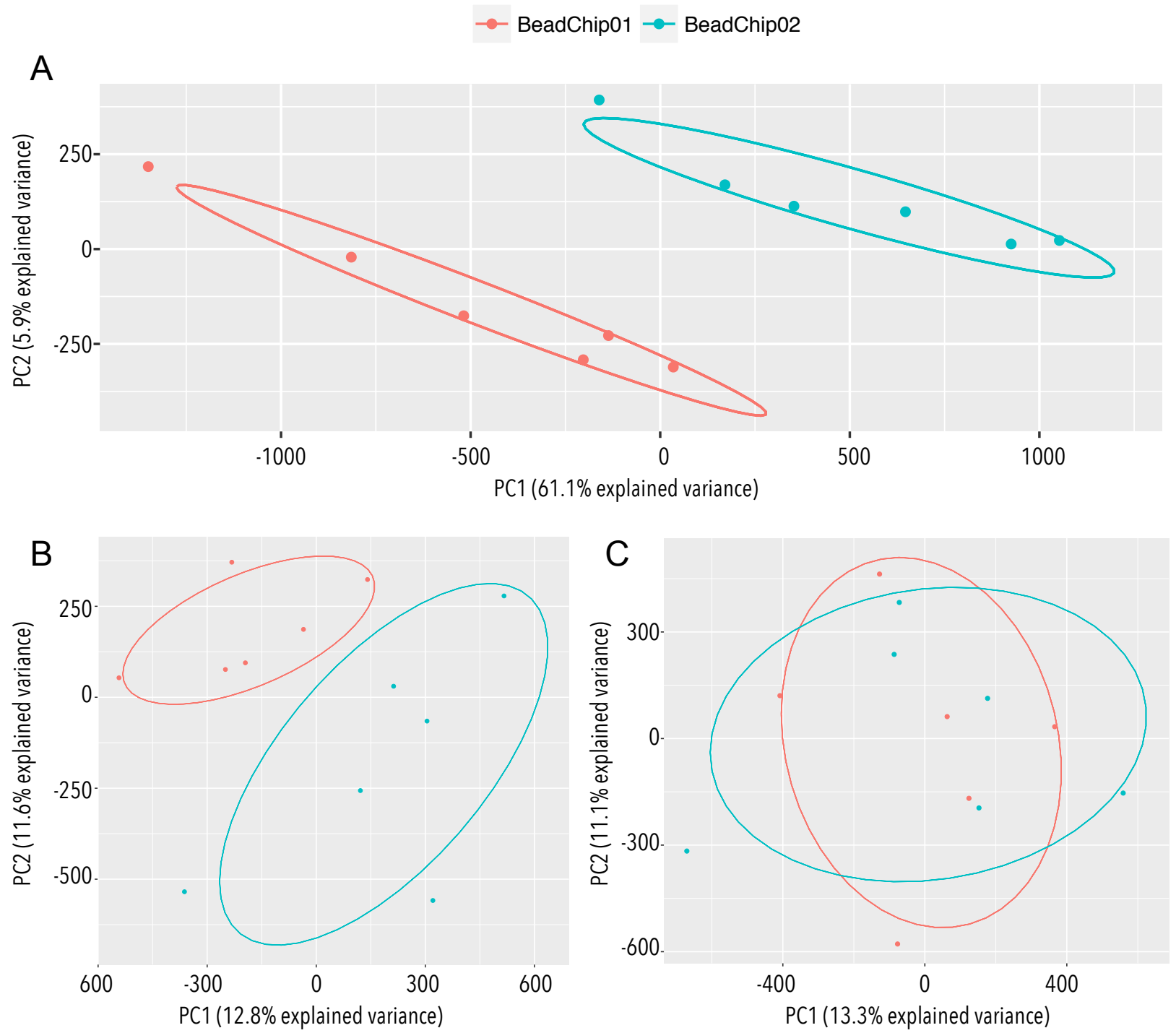

Principal component analysis (PCA) of samples showed a batch effect on the raw methylation values (preprocessRaw) (A). The batch effect was partially corrected after Funnorm pre-processing (B) and was lost after application of the Combat tool (C). Each BeadChip analysed the same number of culture replicates ( $\mathrm{n}=2$ per treatment group). Thus, differences identified by PCA could not reflect differences due to treatments (CTRL, 22:6n-3 or 18:1n-9). 


\section{Supplemental Figure 3.}

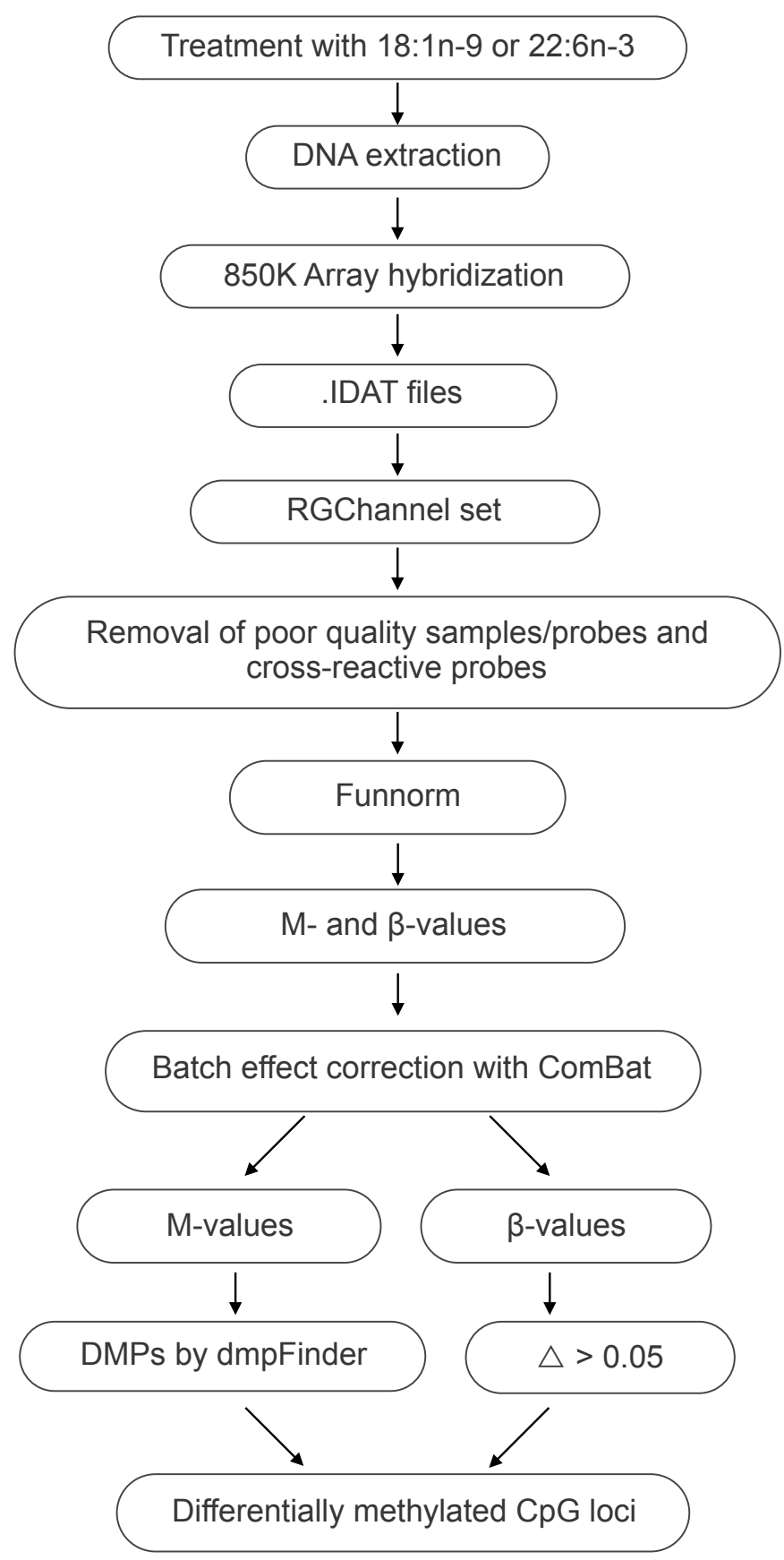

Overview of $850 \mathrm{~K}$ analysis workflow using R package minfi. Funnorm, Functional Normalisation; DMPs, differentially methylated positions; $\Delta$, difference from controls. 


\section{Supplemental Figure 4.}

Differentially methylated CpG loci $\quad$ CpG loci with no change

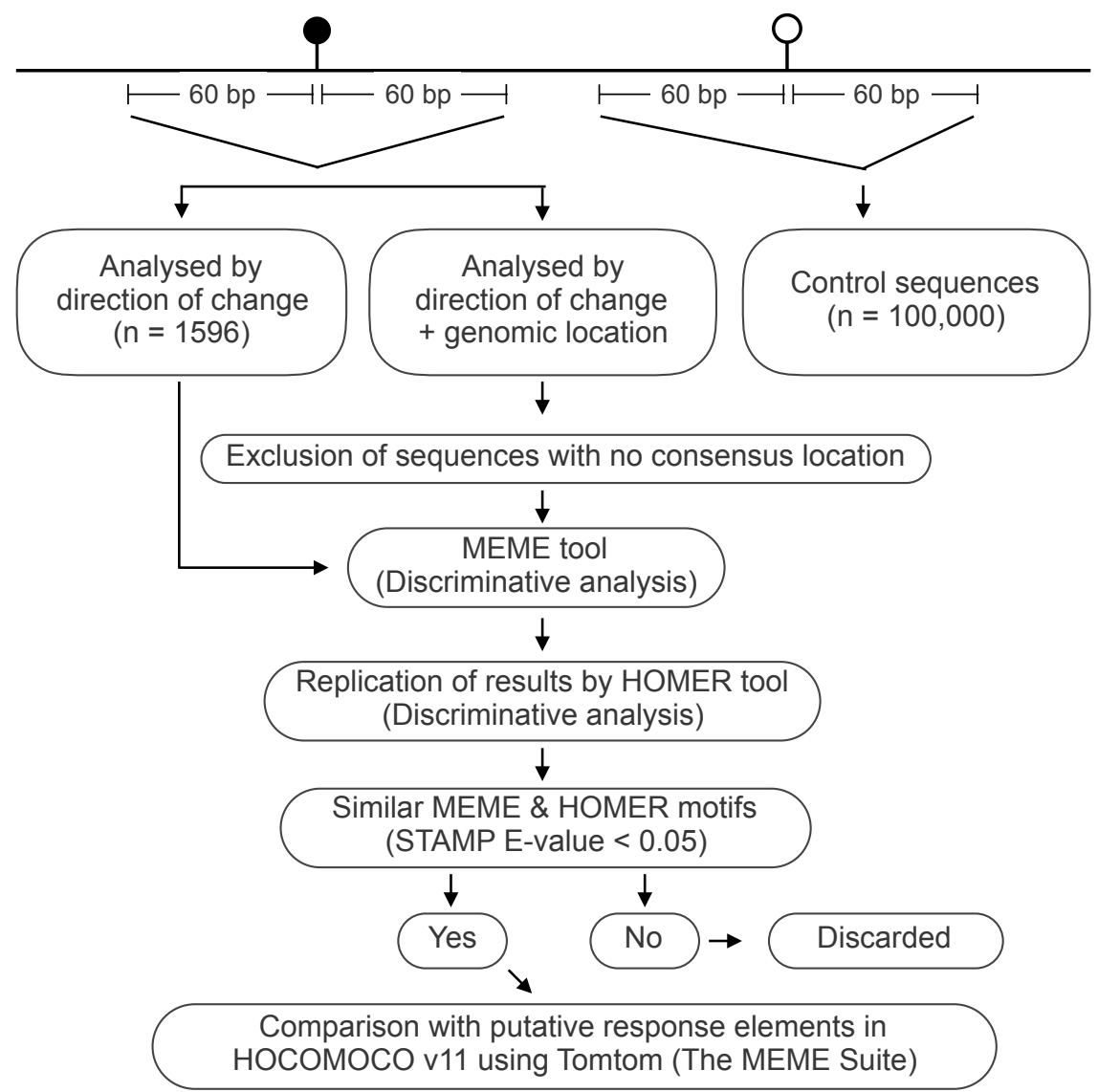

Overview of DNA motif analysis workflow. MEME, Multiple Expectation maximisation algorithm for Motif Elicitation; HOMER, Hypergeometric Optimisation of Motif EnRichment; STAMP, similarity, tree-building, and alignment of DNA motifs and profiles; HOCOMOCO, HOmo sapiens COmprehensive MOdel Collection. 